\title{
Effects of size and position of openings on in-plane capacity of unreinforced masonry walls
}

\author{
Zhen $\mathrm{Liu}^{1} \cdot$ Adam Crewe $^{1}$ (1)
}

Received: 6 December 2019 / Accepted: 13 June 2020 / Published online: 23 June 2020

(c) The Author(s) 2020

\begin{abstract}
In recent earthquakes, unreinforced masonry (URM) structures built of masonry walls containing openings such as doors and windows have been shown to have poor seismic capacity. However, although different sizes and positions of openings are known to reduce the stiffness and strength of URM walls, the relationships between the size and position of openings and seismic capacity of the walls are not clear. Therefore, a series of numerical analyses has, for the first time, explored many possible opening sizes and opening positions under simulated seismic loading to identify their impact on the in-plane behaviour of URM walls. The numerical models were built using the code "3DEC" which is based on the discrete element method (DEM). The key feature of the DEM is that it allows the development of large displacements between elements with contacts being recognized automatically during the analysis. Thus, this numerical method can capture the whole degradation progress from the initial cracking of the masonry walls right through to collapse, with the bricks being modelled as rigid blocks and the mortar as Coulomb-slip joints with zero thickness. Both load-based and displacement-based quasi-static pushover analysis procedures have been studied and the modelling methodology and the calibration of numerical models is described. The results from the analyses, the crack patterns and collapse mechanisms of the masonry walls are identified and discussed, and a key output from this work is the characterization of the relationships between the sizes and positions of openings and the in-plane performance of URM walls.
\end{abstract}

Keywords URM structures · Opening effects · Discrete element method · 3DEC · In-plane behaviour

Adam Crewe

A.J.Crewe@bristol.ac.uk

Zhen Liu

zl15471@bristol.ac.uk

1 Department of Civil Engineering, University of Bristol, Bristol, UK 


\section{Introduction}

Unreinforced masonry structures (URM) are built throughout the world, but in recent earthquakes (Basset-Salom and Guardiola-Víllora 2014; Ingham and Griffith 2010; Lourenço et al. 2013; Parisi and Augenti 2013; Zhang and Jin 2008) their seismic capacity has been shown to be poor. Opening effects, including opening size and opening position, have been shown to affect the extent of damage and failure modes of the walls. Openings reduce the stiffness of masonry walls and can even change the failure mechanisms of the masonry walls. Several studies have been published describing the impact of openings on masonry infill walls e.g. Al-Chaar et al. (2003), Mohammadi and Nikfar (2012), Asteris (2003) and Kakaletsis and Karayannis $(2007,2008)$ and Asteris et al. (2016). These researchers have identified the relationships between stiffness reduction and opening sizes for masonry infill walls and have proposed equations to reflect the influence of openings on the wall stiffness. However, little research has considered the impact of openings on URM structures and it is important to develop similar relationships between opening percentages and strength reduction for openings such as windows and doors. In addition, when the asymmetric location of the openings creates irregular walls or the openings become large, a non-uniform distribution of gravity loads can develop in the masonry walls resulting in a concentration of strength and displacement demands in local parts of the walls. This can lead to local failure and increase the seismic vulnerability of the entire structure (Parisi and Augenti 2013). BS EN1998-1 (2004) gives methods for the simplified design of masonry walls divided by openings but it does not provide any methods for dealing specifically with the effects of openings. Therefore, more analytical work is needed to develop an integrated approach to the behaviour of URM taking into account both opening sizes and opening positions.

Typical URM structures include load-bearing walls arranged in orthogonal planes and rigid or flexible floors (Magenes and Calvi 1997). Damage to URM buildings in earthquakes comprises both out-of-plane failures and in-plane failures of the walls. The in-plane walls are critical in URM structures as they provide the stability and strength to prevent the collapse of the buildings. Usually, these in-plane walls are divided into small piers and spandrels by window openings and door openings. These smaller structural components, separated by openings, form the system that resists gravity and lateral loads. The failure of masonry walls under in-plane loading is generally caused by one of (a) compressive failure at the toe of the wall, (b) flexural failure or (c) shear failure along the mortar joints. These effects can also be described as (a) rocking failure, (b) diagonal tension cracking and (c) bed-joint sliding as shown in (Fig. 1). It is important to consider the impact of openings on all of these failure mechanisms for URM walls under in-plane loading and then identify the variation of lateral strength and displacement capacity of URM walls when there are openings present.

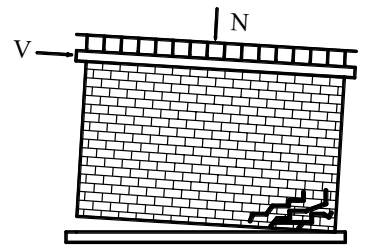

(a) Rocking failure

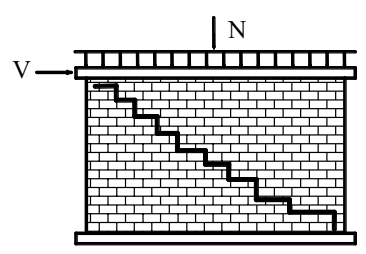

(b) Diagonal cracking

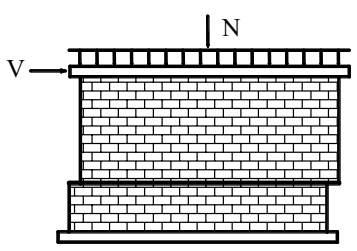

(c) Bed-joint sliding

Fig. 1 Failure patterns of masonry walls 
In order to identify the impact of openings on URM via parametric studies, appropriate numerical analysis techniques are needed. Based on the failure modes of masonry blocks (Chaimoon and Attard 2007; Korswagen et al. 2019; Petry and Beyer 2015; Wilding and Beyer 2017), there are two main computational methods for modelling brick masonry, (a) micro-modelling of brick units and (b) macro-modelling the walls as a composite structure (Milani 2016). A detailed micro-modelling approach is arguably the most accurate method for simulating masonry brick behaviour; however, it is time-consuming to run analyses and only can readily be applied to small masonry walls. In contrast, the macromodelling approach can model large scale structures efficiently, however it cannot capture the detailed failure mechanisms properly (Lourenco and Rots 1994; Lourenco 1996). The discrete element method (DEM) belongs to a simplified micro-modelling method and is suitable for masonry structures because large displacements can be applied, and failure mechanisms are also easily observed. The DEM was first introduced by Cundall (1971), who developed the formulation for this method where finite displacements and rotations of discrete bodies are allowed and contacts between bodies are recognized automatically. The DEM has now been used in many areas where the contacts between bodies or particles need to be identified and, as such, is it particularly suitable for application to masonry structures. Alexandris et al. (2004) applied the DEM successfully to model the collapse mechanisms of historic masonry structures. Dimitri et al. (2011) used DEM to create a 2D numerical study on the dynamic behaviour of masonry columns and arches. Lemos (1998, 2004, 2007) studied masonry arches using the DEM and extended the modelling masonry structures into 3D using the DEM code 3DEC. More recently, de Felice (2011) studied the out-of-plane behaviour of masonry walls with varying wall section morphology and proposed methods to determine the failure acceleration under quasi-static loading. Çakt1 et al. (2016) developed an experiment of a scaled masonry structure and compared the dynamic response with a 3DEC model. Similarly, Lemos and Campos Costa (2017) simulated simplified shaking table tests of masonry stone structures and compared the results with experimental data. Their paper demonstrated that the DEM could reproduce all the significant features of the shaking table tests. In Sarhosis et al. (2014, 2015), Sarhosis and Sheng (2014) and Giamundo et al. (2014), low-bond strength masonry walls were built in 3DEC to study in-plane masonry behaviour. These papers introduced specific methods for modelling masonry in 3DEC and compared the load-displacement curves for different factors such as tensile strength, cohesion and friction angle. Bui et al. (2017) developed a 3D DEM numerical model to study the in-plane and out-of-plane behaviour of dry-joint masonry wall construction. Their article describes the simulated collapse patterns and compares them with experimental data; with the simulated and experimental data agreeing well. An example comparing 3DEC analyses with experimental data for plain and reinforced masonry walls can be found in Dihrou et al. (2018) and a 3DEC model of masonry wall was built by Liu and Crewe (2018) to explore the effects of opening on masonry walls.

This paper expands on this body of knowledge by identifying the relationships between both the opening position and opening percentage on the in-plane load capacity and the displacement capacity of URM walls. A DEM approach is used to model the masonry walls and the modelling method and material properties are presented. Many different opening percentages and opening positions are analysed and some specific cases, such as varying the opening shape and numbers of openings in a wall, are also considered. Calibration of the numerical models against previous experimental and numerical work is also carried out to verify the reliability of the modelling technique. Finally, explicit relationships between the opening size and location, and the in-plane performance of the masonry walls are presented considering the potential failure patterns induced by the openings. 


\section{Discrete element modelling of URM structures using 3DEC}

3DEC is software based on the UDEC code (Universal Distinct Element Code) and is derived from DEM theory. Many different systems have been explored using 3DEC, such as masonry structures, stone masonry and masonry arch bridges (Milani 2016). In 3DEC, Itasca (2012), the representations of blocks and contacts are considered and a procedure to create non-convex blocks by joining convex components has been developed. The current version of the code also includes an internal programming language, called FISH, which allows automation of model generation, lending itself to automatic generation of models for parametric studies. The 3DEC software also allows monitoring of data at any location during the analysis and a user can build specific behaviour indicators based on their needs. At any stage in the analysis, user-defined data can be recorded and plotted to reflect the response of the system.

\subsection{Assumption of blocks and contacts}

The simplest representation of blocks in 3DEC assumes that they are rigid bodies with deformations only allowed at interfaces. The blocks are characterized by polygons that need to be convex, therefore, to create non-convex blocks, convex sub-blocks are created and then 'glued' together so that they move as one unit without relative displacement. As an alternative to modelling the blocks as rigid bodies it is possible to create deformable block models where the individual blocks are also meshed as in FE models. The simple meshing used by 3DEC within the deformable blocks allows the modelling of bending behaviour, but each block would need a detailed and complex meshing if weaker materials with stress concentrations were to be modelled more accurately. When running static analyses, the choice between rigid and deformable blocks leads to slight differences in repeatability of results. For rigid blocks the analyses are repeatable but for deformable blocks the random meshing process used by the software leads to slightly different results for each analysis. In general, the time taken for a static analysis with either type of block is similar because of the efficiency of the code; however, for a dynamic analysis, the use of rigid blocks results in a significant reduction in analysis time because there is no requirement to calculate the internal stresses in the blocks at each time step as is necessary for deformable blocks.

The representation of contacts in discrete element (DE) models generally assumes that contact only occurs between points, and that the interaction between blocks is reflected by these contact points. This contrasts with the discontinuous FE method where joint elements are used to create a relationship between forces and displacements. A DE model is ideal for modelling contacts between faces and true point contacts like vertex-edge contacts. Furthermore, there is no need to consider matching the nodal points when meshing the blocks, meaning the blocks can be meshed independently. Thus, any stress distributions calculated in DE models, assuming the meshing is sufficiently fine, should be more accurate than in FE models with joint elements. These two contact assumptions can be seen in Fig. 2.

Lemos (2007) outlines two different contact types for DE models, (a) hard contact and (b) deformable contact. The hard contact assumption is mainly useful for linear rigid block problems where no overlaps can be tolerated. For deformable contacts, both normal and shear contact stiffness are defined, and the interaction forces are defined by the overlap of the joints. It is notable that, in the case of mortared joints, the normal stiffness can be 


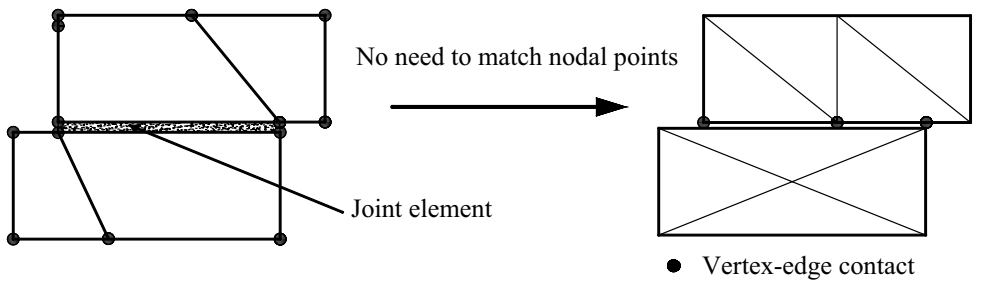

(a) Representation of contact by joint element

(b) Representation of contact by point (vertex-edge)

Fig. 2 Representation of contact between blocks. [Adapted from Lemos (2007)]

calculated from the mortar properties, however, for dry joints, irregular contacts can result in stress concentrations so that appropriate contact stiffnesses need to be determined via experiments. For modelling shear contacts a Coulomb friction model is used. Thus, the normal contact force and the shear force can be calculated from the normal and shear stiffnesses, the relative contact displacements and the contact area. Finite tensile and shearbond strengths can also be incorporated into the joint properties to reproduce the correct fracture energy under post-peaking softening and prevent numerical perturbation caused by sudden bond failure. As the main failure mechanism of URM walls is controlled by the failure of joints (Sarhosis and Sheng 2014), it is appropriate to use rigid blocks for modelling and this also improves the efficiency of the analyses.

\subsection{Models of block and joint}

Three basic constitutive models for blocks exist in 3DEC: an elastic isotropic model; an elastic anisotropic model and a Mohr-Coulomb plasticity model (Itasca 2012). Of these, the elastic isotropic model is the simplest material model and this simplifies to a rigid block if only density is defined. While the use of rigid blocks does not allow modelling of local brick crushing or failure, because masonry walls usually fail along the joints (Bruneau 1994; Çaktı et al. 2016; Lourenco 1996; Sarhosis and Sheng 2014) rather than through the blocks, this modelling approach remains valid for global modelling of walls, at least up to the point where significant cracking has concentrated local stresses to the point that bricks would start to experience local failure. Therefore, this research adopts rigid block modelling as it focusses on maximum wall capacities rather than final collapse mechanisms. However, other brick material models could be used if the final collapse mechanisms were of specific interest.

In 3DEC, the joints between the blocks are represented by a zero-thickness interface between adjacent blocks, as mentioned in 2.1. Along with the interfaces, contacts are defined at the edges or corners of the blocks and they are connected by two assumed springs such that they can transfer normal and shear forces between the blocks, as illustrated in (Fig. 3). A coulomb-slip joint model is the basic constitutive joint model employed in 3DEC, and all the sub-contacts between the blocks follow the Coulomb friction rules; with shear failure, tensile failure and joint dilation all being modelled. In the elastic range, the behaviour is governed by the joint stiffness, shear stiffness and tensile strength, whilst, during the plastic stage, the behaviour is controlled by cohesion, frictional angle and dilatation angle. Once either tensile or shear failure takes place, both the cohesion and tensile strength are set to zero while the friction angle is maintained. Therefore, after the first 


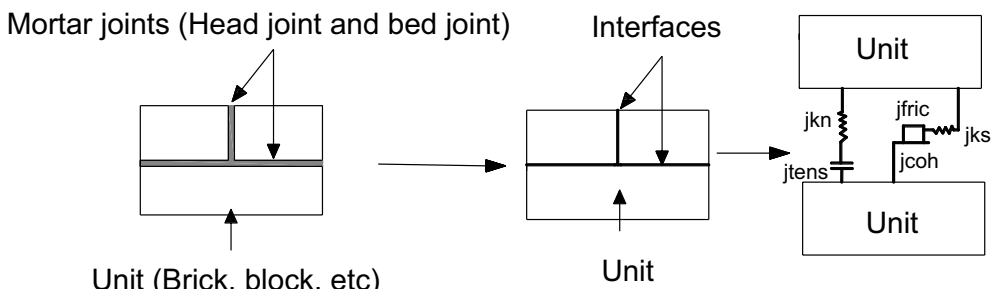

Fig. 3 Interface model. [Adapted from Çaktı et al. (2016)]

failure of the joint, the joint behaviour is controlled solely by friction. Based on Itasca (2012), in the elastic range, the behaviour can be defined by the joint normal stiffness and shear stiffness, $K_{n}$ and $K_{s}$ and the formulation is described below (taking compressive force as positive):

$$
\begin{gathered}
\Delta F^{n}=-K_{n} \Delta U^{n} A_{c} \\
\Delta F_{i}^{s}=-K_{s} \Delta U_{i}^{s} A_{c}
\end{gathered}
$$

where $\Delta F^{n}$ is the normal force vector increment, $\Delta U^{n}$ is the normal displacement vector increment, $\Delta F_{i}^{s}$ is the shear force vector increment, and $\Delta U_{i}^{s}$ is the shear displacement vector increment, $A_{c}$ is the area of the sub-contact.

For an intact joint (without previous slip or separation), the tensile normal force is given by

$$
T_{\max }=-T A_{c}
$$

where $T$ is the joint tensile strength.

The maximum shear force is calculated as

$$
F_{\text {max }}^{s}=c A_{c}+F^{n} \tan \emptyset
$$

In which $\mathrm{c}$ is the interface cohesion (stress) and $\emptyset$ is friction angle, when the onset of failure is identified at the sub-contact, in either tension or shear, the tensile strength and cohesion are taken as zero:

$$
\begin{gathered}
T_{\text {max }}=0 \\
F_{\text {max }}^{s}=F^{n} \tan \emptyset
\end{gathered}
$$

\subsection{Quasi-static analysis and failure criteria}

For pushover analyses of multi-storey buildings, as described by BS EN1998-1 (2004), a non-linear static analysis is carried out under conditions of constant gravity load and monotonically increasing horizontal loads, with the lateral loads being applied at the location of the masses in the building, typically each floor level. For low-rise masonry buildings, in which structural wall behaviour is dominated by shear, BS EN1998-1 (2004) additionally states that each storey may be analysed independently. Therefore, in this paper single storey 
masonry walls are analysed and two different loading methods have been used to simulate in-plane seismic loading on the walls.

In the first case a load-based analysis is performed by applying a gradually increasing horizontal acceleration to the whole URM wall to create the pushover analysis, where every brick experiences a force proportional to its mass. Initially the vertical gravity load is applied, then a uniform horizontal acceleration is applied to the masonry wall, in increments, until failure takes place. This type of loading emulates the inertia generated loading that occurs in a seismic event-albeit only in a pseudo-static way. To determine the failure load, the horizontal displacements need to be monitored carefully at each load step. Under this type of load-based analysis, once failure takes place, the horizontal displacements increase dramatically. Therefore, the displacement at each load step is monitored and the ultimate capacity of the wall is based on the flattening of the acceleration/displacement curve. The base shear force was also calculated using a customised function in 3DEC to allow generation of force/displacement curves. This type of load-based pushover analysis procedure is simple and fast; however, the displacements and failure patterns cannot be found after the maximum load is reached. Therefore, a displacement-based pushover analysis method was also implemented, which allowed tracking of any post-peak softening but required more computation as the displacement needed to be applied at a low velocity to allow a smooth response to be simulated.

In 3DEC, the displacement-based pushover analysis was achieved by applying constant velocity to a loading block at the top of the wall after the vertical gravity load had been applied to the wall. It was important, for the displacement-based analysis procedure, to validate whether the deformation and failure process was smooth or whether any artificial vibration motion occurred, and if so, the loading velocity was reduced so that the loading was effectively quasi-static. In order to obtain the collapse load, the reaction forces being applied at the prescribed velocity boundaries were calculated at every time step (Sarhosis et al. 2014). Force/displacement curves were again calculated using a customised function for comparison with similar data from the load-based analyses. While this type of displacement-based analysis allowed tracking of any post-peak softening and captured the failure patterns in the masonry, the loading pattern is less representative of the forces on a URM wall under seismic loading as the loading is only applied at a single point at the top of the wall. However, if significant loading on the URM wall is coming from a supported floor or roof, then it is more reasonable to ignore the forces generated by the mass of the URM wall itself. This type of displacement-based loading regime is also commonly used in experimental test programmes.

Because both the load-based and the displacement-based analysis procedures offer difference advantages both methods have been used in this paper to create pushover curves for URM walls with openings. It is particularly relevant to compare results from a displacement-based single point loading regime, which is widely used in experiments, with a load-based distributed loading procedure which is more representative of actual loading in a seismic event, to identify any differences in in-plane capacities and in failure patterns.

\subsection{Vertical load, mechanical damping and mass (density) scaling}

In 3DEC vertical pre-compression loads can be applied to models, in additional to normal gravity loads, followed by a few analysis cycles to settle the structure into an elastic equilibrium. This vertical pre-compression can be achieved by applying vertical boundary 
stress, or by adding a top block and simulating the vertical pre-compression by altering the density of this top block. The second approach was adopted in this research.

A static 3DEC analysis actually uses a dynamic solver (Itasca 2012) and mechanical damping is used to help improve stability of the 'static' solver. For static problems, the approach used is similar to that used in dynamic relaxation solvers and the procedure applies a damping force proportional to the velocity of blocks (velocity-proportional damping). There are two forms of velocity-proportional damping including in 3DEC, namely adaptive global damping and local damping. The global damping approach adjusts the damping constant automatically and applies viscous damping forces to the blocks. The local damping approach applies a damping force to each block node proportional to the magnitude of the unbalanced force on the block. Both damping approaches converge to the same solution, but the local damping approach is preferable when solving problems where there is the possibility of sudden load changes or failure within the model. In this research local damping was used (with a default value of 0.8 ).

Mass scaling is a way to speeding the convergence of static problems continuing very non-uniform block sizes to increase the efficiency of calculation. It is mainly useful when the model is non-uniform and is normally applied to the quasi-static problem. In 3DEC, a check for whether mass scaling is helpful is automatically activated if either local damping or global damping is being used, however because the models being studied did not contain any very small blocks no mass scaling was actually applied.

\section{Validation of 3DEC for modelling masonry}

\subsection{Comparison of 3DEC with an experimental monotonic pushover test of a masonry wall}

To assess the reliability of 3DEC for in-plane static analysis of URM, data from an experimental test of a masonry wall (Augenti et al. 2010; Parisi 2010) was compared with 3DEC analyses. The geometry of the masonry wall test is shown in (Fig. 4). Table 1 gives the mechanical properties of the masonry taken from the experimental data: tensile strength $f_{t}$; compressive strength $f_{c}$; Young's modulus $E$; and shear modulus $G$. The mechanical parameters of the masonry were identified both parallel and orthogonal to the mortar bed joints to allow individual modelling of the spandrel and piers respectively. Based on the properties in Table 1, and the calculation methods of joint stiffness and strengths given in Sect. 4.2, the properties of joints for the 3DEC model were calculated and are given in Table 2. The density of bricks was taken as $1600 \mathrm{~kg} / \mathrm{m}^{3}$ and two $100 \mathrm{kN}$ vertical load blocks were applied at the top of the piers. To simulate this experiment in 3DEC, a constant velocity was applied to a loading block. The horizontal force in, and displacement of this block were recorded, and relevant masonry crack patterns and pushover curves were obtained.

Figure 5 shows the failure patterns in the experimental specimen, including (a) a graphical interpretation and (b) a photo of the crack patterns in the masonry wall from Parisi (2010) and Augenti et al. (2010).

The 3DEC analysis produced very similar crack patterns to the experimental tests, with the numerical model (Fig. 5c) displaying diagonal cracks in the middle part of the horizontal beam component and rocking failure at the bottom of the piers. The 3DEC and experimental pushover curves are also similar (Fig. 5d). While the experimental 


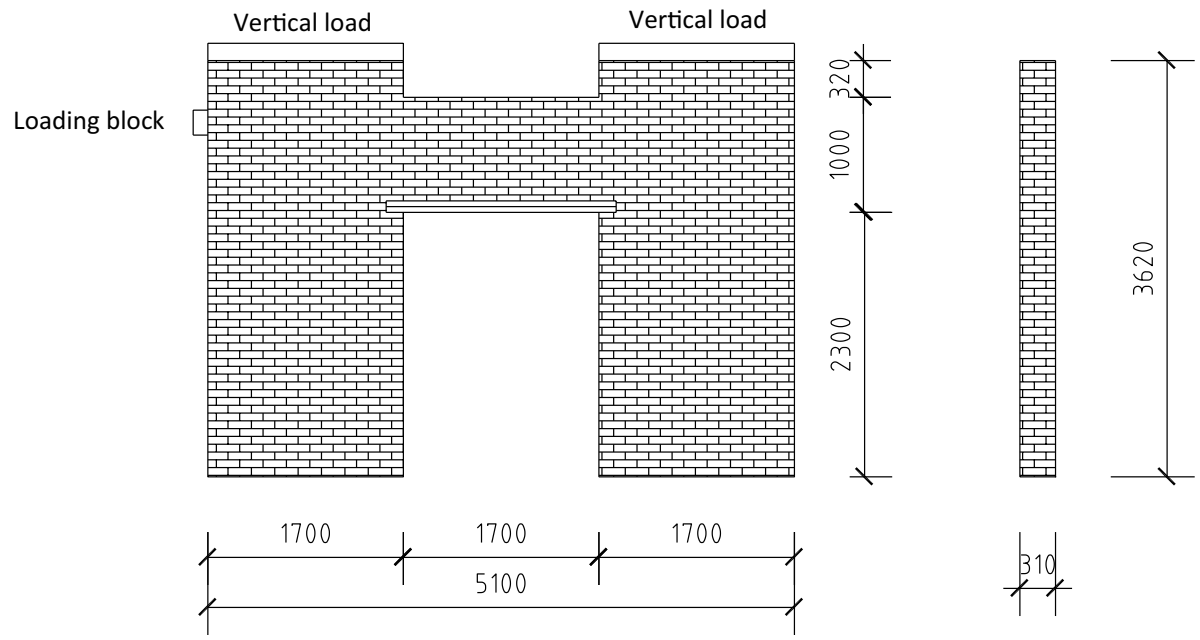

Fig. 4 Geometry of experimental specimen (dimensions in mm). [Adapted from Parisi (2010)]

Table 1 Mechanical properties of constituent materials

\begin{tabular}{|c|c|c|c|c|}
\hline & $f_{t}(\mathrm{MPa})$ & $f_{c}(\mathrm{MPa})$ & $E(\mathrm{GPa})$ & $G(\mathrm{GPa})$ \\
\hline Pozzolana-like mortar & 1.43 & 2.50 & 1.52 & 0.66 \\
\hline $\begin{array}{l}\text { Tuff masonry } \\
\text { (compression parallel to bed joints) }\end{array}$ & - & 3.85 & 2.07 & 0.86 \\
\hline $\begin{array}{l}\text { Tuff masonry } \\
\text { (compression orthogonal to bed joints) }\end{array}$ & - & 3.96 & 2.22 & 0.92 \\
\hline
\end{tabular}

Table 2 Material properties used in 3DEC for modelling of the joints

\begin{tabular}{lcllll}
\hline & $\begin{array}{l}\text { Joint normal stiff- } \\
\text { ness }(\mathrm{MPa} / \mathrm{m})\end{array}$ & $\begin{array}{l}\text { Joint shear stiff- } \\
\text { ness }(\mathrm{MPa} / \mathrm{m})\end{array}$ & $\begin{array}{l}\text { Joint friction } \\
\text { angle (Degrees) }\end{array}$ & $\begin{array}{l}\text { Joint tensile } \\
\text { strength (MPa) }\end{array}$ & $\begin{array}{l}\text { Joint } \\
\text { cohesion } \\
(\mathrm{MPa})\end{array}$ \\
\hline Vertical joints & 6680 & 2770 & 35 & 0.8 & 1.6 \\
Horizontal joints & 20,200 & 8360 & 35 & 0.8 & 1.6 \\
\hline
\end{tabular}

specimen displayed a lower maximum horizontal capacity compared to 3DEC when using the tensile and cohesion properties of the mortar given in the experimental data (Table 2), it is worth noting that the model is sensitive to these properties and a $50 \%$ reduction (i.e. from 1.6 $\mathrm{MPa}$ to $0.8 \mathrm{MPa}$ ) in the cohesion value used for the joints resulted in a much closer match to the peak wall capacity. Results from the 3DEC model with the original properties had a mean difference of $+16 \%$ (i.e. predicted higher forces) and an RMS difference of $23 \%$ compared to the experimental data, while the 3DEC model with modified cohesion values had a mean difference of $-9 \%$ and an RMS difference of $17 \%$ compared to the experimental data (these statistics are calculated over the displacement range of the experimental data). Another reason for differences in the 

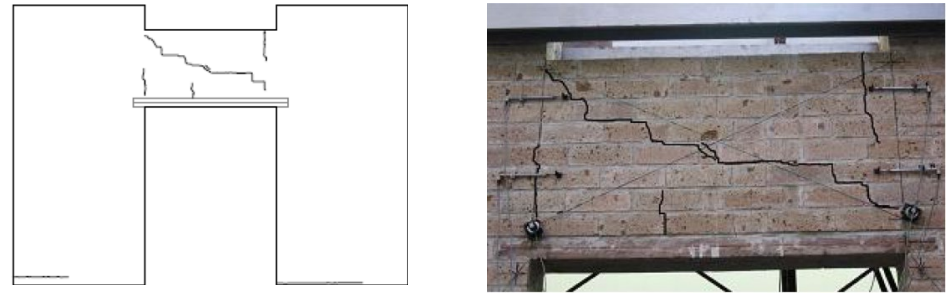

(a) Damage pattern for the masonry wall (from (Augenti et al. 2010) with permission from ASCE); (b) Crack development in the masonry wall (From (Augenti et al. 2010))

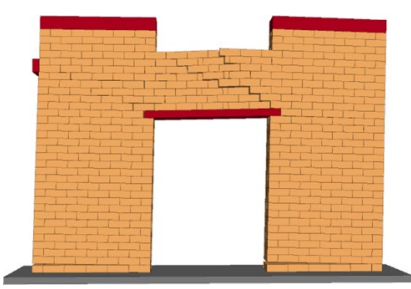

(c) Damage pattern for the masonry wall in $3 \mathrm{DEC}$

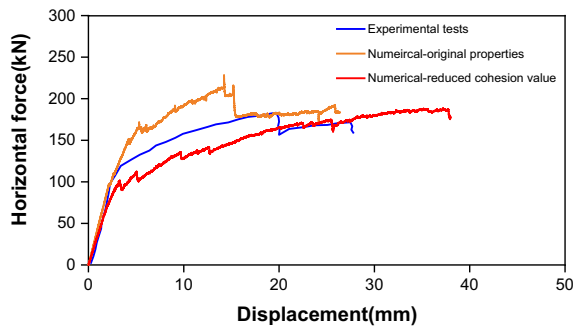

(d) Comparison of pushover curves from 3DEC with experimental

Fig. 5 Comparison of crack patterns and pushover curves for the experiment and the 3DEC model

curves is that the bricks in the 3DEC model were modelled as rigid blocks (ignoring the possibility of crushing or cracking of the masonry) with failure controlled only by the properties of joints. Thus the numerical model could be expected to be stronger than the experiment, where some local cracking of the masonry bricks was evident during the testing (Fig. 5b). While it is possible to create a 3DEC model that incorporates elastic, elastic-plastic, or even cracking blocks, rather than rigid blocks, the simpler rigid block modelling approach remains valid at least until significant cracking has concentrated local stresses to the point that bricks would start to experience local failure. This comparison shows that numerical modelling in 3DEC can simulate the quasi-static behaviour of URM walls and is appropriate for modelling pushover tests.

\subsection{Comparison with experiments on dry-joints masonry walls under in-plane behaviour}

To further check the validity of numerical models in 3DEC, a model of a simple dryjointed masonry wall was built and was subjected to combined shear and vertical precompression loads for comparison published experimental data (Lourenço et al. 2005). Models of four wall sections (wall I, wall II, wall III and wall IV) with different vertical loads applied (30 kN, $100 \mathrm{kN}, 200 \mathrm{kN}$ and $250 \mathrm{kN}$ ) were analysed to observe the different failure crack patterns and maximum horizontal loads. The size of all the masonry walls was $1000 \mathrm{~mm} \times 1000 \mathrm{~mm} \times 200 \mathrm{~mm}$ (height $\times$ span $\times$ breadth) and the blocks were $100 \mathrm{~mm} \times 200 \mathrm{~mm} \times 200 \mathrm{~mm}$ (height $\times$ span $\times$ breadth) in dimension. The density of blocks was $2200 \mathrm{~kg} / \mathrm{m}^{3}$, the Young's modulus of blocks was $15,500 \mathrm{~N} / \mathrm{mm}^{2}$ and the Poisson's ratio was 0.2. The joint properties were determined using equations from Lourenço et al. (2005) and Bui et al. (2017) and took into account measurements of the variation of the stiffness of 


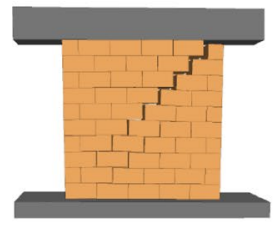

(a) Crack patterns for wall I - 30kN vert. load
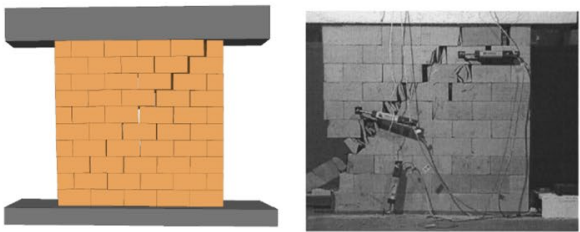

(c) Crack patterns for wall III - $200 \mathrm{kN}$ vert. load
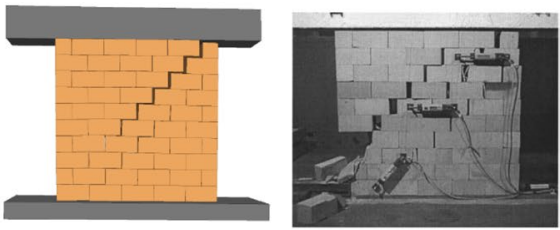

(b) Crack patterns for wall II - 100kN vert. load
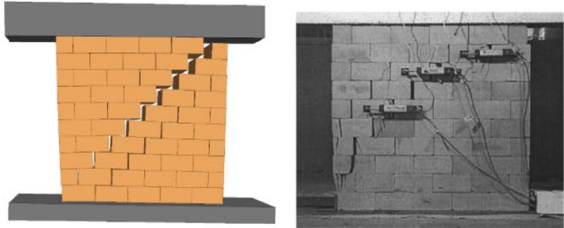

(d) Crack patterns for wall IV $-250 \mathrm{kN}$ vert. load

Fig. 6 Crack pattern comparison: Numerical models and experiment data. [From Lourenço et al. (2005) with permission from ASCE]

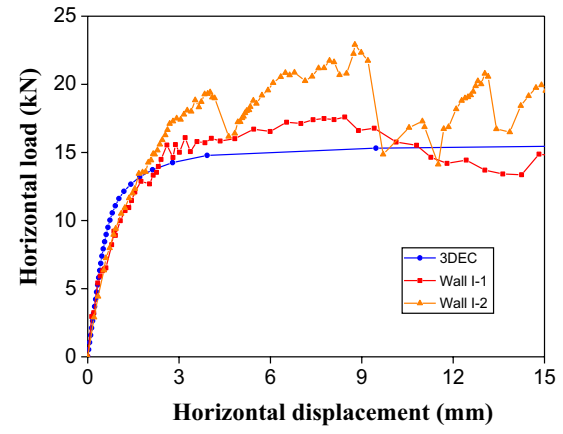

(a) Experiment and 3DEC model for wall I

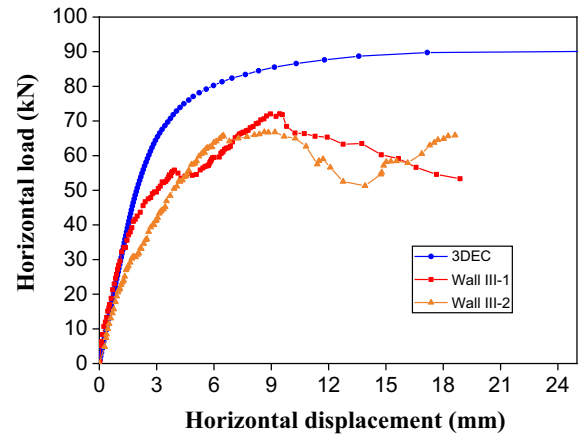

(c) Experiment and 3DEC model for wall III

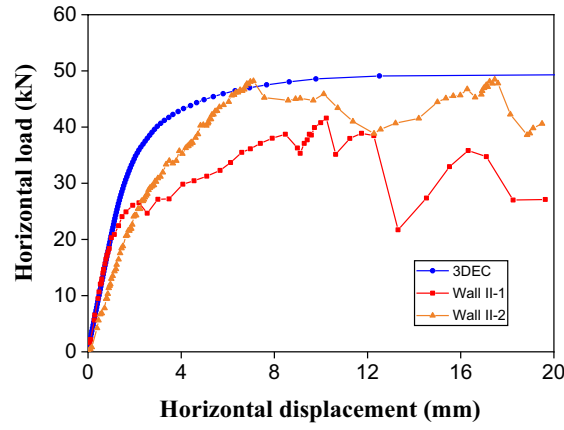

(b) Experiment and 3DEC model for wall II

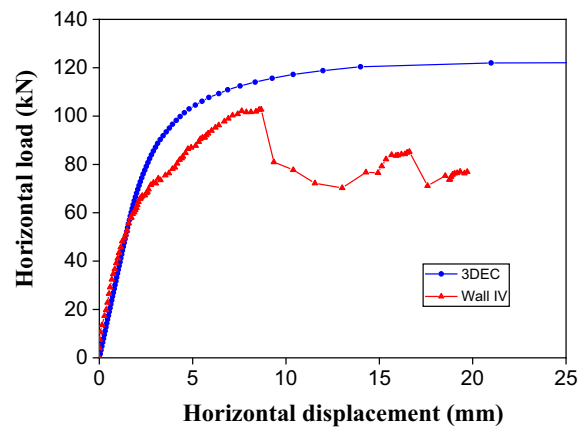

(d) Experiment and 3DEC model for wall IV

Fig. 7 Load-deflection curve comparison: Experiment and 3DEC models 
the walls with the applied vertical load. A comparison of crack patterns for the numerical and experimental tests is shown in Fig. 6 and load displacement plots are shown in Fig. 7.

Comparing the crack patterns for the numerical and experimental data, it can be seen that the 3DEC numerical models show very similar failure crack patterns to the experiments (Bui et al. 2017). The main failure modes in the 3DEC models are the de-bonding of the top concrete beam and a diagonal crack, as happened in the experimental tests. For all the wall cases (I-IV) the mean $(-6 \%,+28 \%,+37 \%,+32 \%)$ and RMS $(14 \%, 31 \%$, $40 \%, 42 \%$ ) differences were calculated relative to the experimental data. For walls I to III the experimental data from the two tests were averaged before calculating the differences, and in all cases the statistics are calculated over the displacement range $0-15 \mathrm{~mm}$ to allow comparison between the walls. The 3DEC models generally overestimated the wall forces by $30 \%$. However, because of the rigid block assumption made in the analyses, the numerical model could not capture the crushing or cracking of the masonry blocks which was seen in some of the experiments. In particular, for the walls with higher vertical loading (Fig. 7c, d), where local block crushing and cracking occurred, the numerical model overestimates the load at failure by up to $30 \%$. This means that some caution is needed when using simplified models if there is a possibility of local block failure.

Overall, the two validation cases presented above show that 3DEC can successfully simulate the quasi-static response of masonry walls under in-plane loading and can reproduce the failure mechanism of these structures. Even though the properties of bricks were simplified for these comparisons, the results are comparable, showing that 3DEC is an appropriate tool for modelling URM under in-plane loading.

\section{Modelling of URM walls in 3DEC}

\subsection{Geometry}

When considering the modelling of a typical URM building, the individual masonry walls can be divided into two categories (1) square walls and (2) rectangular walls, as illustrated in Fig. 8a, b (Abrams and Shah 1992, Ghiassi et al. 2012). Geometric models
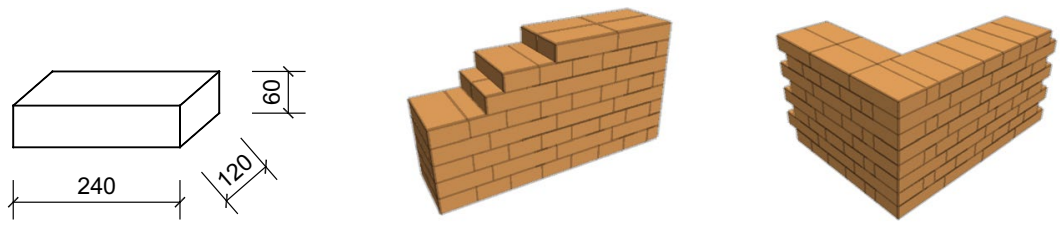

(Left) The size of brick; (Middle) Brick with Flemish bond; (Right) The connection of corner for Flemish bond wall

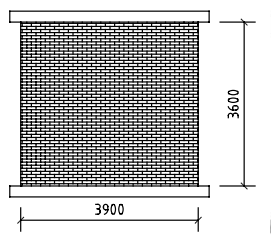

(a) Wall I elevation and Numerical model in 3DEC

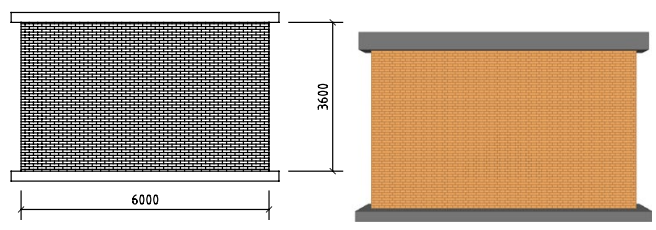

(b) Wall II elevation and numerical model in 3DEC

Fig. 8 Geometry and numerical models of different masonry walls in 3DEC 
both types of masonry walls, with typical dimensions, were built in 3DEC. To replicate the response of realistic URM walls, the models were built using a Flemish bond, the size of each masonry block was set as $0.06 \mathrm{~m} \times 0.24 \mathrm{~m} \times 0.12 \mathrm{~m}$ (height $\times$ length $\times$ depth), and the dimensions of masonry walls were $3.9 \mathrm{~m} \times 0.24 \mathrm{~m} \times 3.6 \mathrm{~m}$ (length $\times$ thickness $\times$ height). Below each masonry walls, a block was created to represent the ground, and an embedded concrete beam with a size of $4.38 \mathrm{~m} \times 0.5 \mathrm{~m} \times 0.24 \mathrm{~m}$ (length $\times$ width $\times$ height) was located at the top of masonry wall where vertical loads would be applied. The detailed geometry of the models is shown in Fig. 8.

\subsection{Material properties of blocks and joints}

To simplify the analytical process, the bricks were modelled using rigid blocks. For this type of rigid block model, the joint stiffness had to represent the stiffness of both the block and joint. If $\mathrm{E}$ and $\mathrm{G}$ are the Young's and shear moduli of the material, then the joint stiffnesses can be calculated using Eqs. (7), (8), (9) as illustrated in Fig. 9.

$$
\begin{gathered}
\text { Horizontal joints } j_{k n}=E / h \text { and } j_{k s}=G / h \\
\text { Vertical joint1 } j_{k n}=E / d \text { and } j_{k s}=G / d \\
\text { Vertical joint2 } j_{k n}=E / l \text { and } j_{k s}=G / l
\end{gathered}
$$

where $h, d$ and $l$ is the dimension of the block plus the joint. It is worth noting that, because the blocks are not square, the joint properties are different between the horizontal joints and vertical joints, even though the mortar thicknesses are the same.

The cohesion properties of the joints in 3DEC are determined using Eq. (4) where $F_{\text {max }}^{s}$ and $T_{\text {max }}$ are calculated from the compressive strength and tensile strength of bricks (based either on design code information or experimental results). The tensile strength of the joints was taken as half the cohesion force, based on Lemos and Campos Costa (2017). For this work the compressive strength of bricks was taken as $1.83 \mathrm{MPa}$, the average tensile strength of mortar as $0.13 \mathrm{MPa}$ and the shear strength of mortar as $0.11 \mathrm{MPa}$. These values coming from the typical strengths defined in the Chinese design code for of masonry structures (GB50003-2011 2012). The friction angle was assumed to be 35 degrees, which is consistent with the values given in Sarhosis and Sheng (2014) for other 3DEC analyses. The final calculated properties used in the 3DEC model are given in Table 3 .

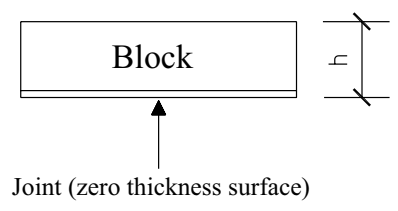

(a) Horizontal joints

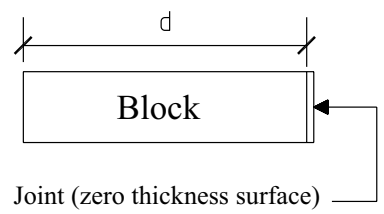

(b) Vertical Joint 1

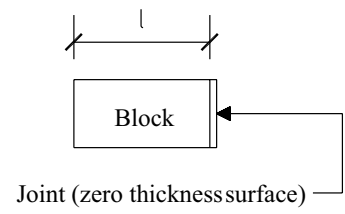

(c) Vertical Joint 2

Fig. 9 The calculation diagram of joint stiffness 


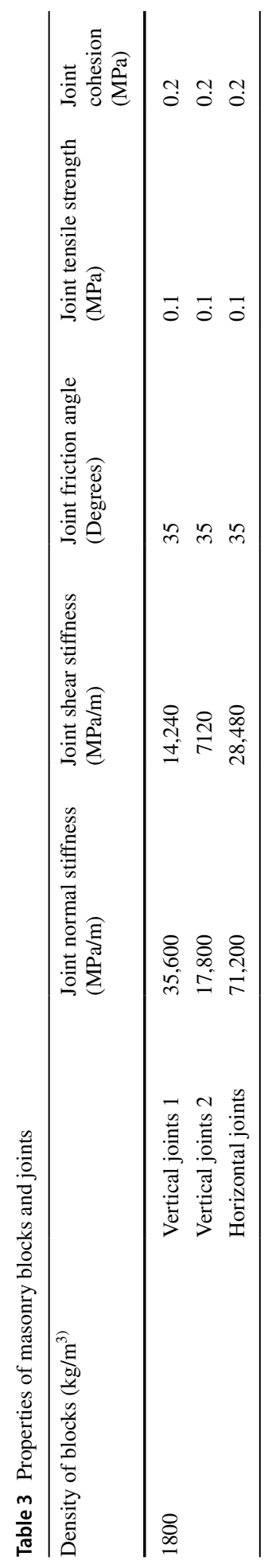




\section{In-plane capacity of masonry walls with different size openings}

\subsection{Cases studied to assess the effect of opening percentage on in-plane capacity}

A total of five types of 3DEC model were built to identify the impact of opening percentage on URM walls. Based on Voon and Ingham (2008), which considered a range of openings in RC masonry infill walls, in this paper, centralised square and rectangular window openings, single door openings, and combined door and window openings in URM walls with different aspect ratios have been all considered. These five different types of masonry wall are shown in Fig. 10. For each basic wall type, the opening sizes were divided into eleven sub cases, identified as OS1 to OS11 with opening percentages varying from about $2-83 \%$, respectively. To allow modelling of the walls using just full and $1 / 2$ size bricks, the actual opening percentages in the five wall types vary slightly, but they have been kept as close as possible for each wall type. Detailed information about the sizes of openings can be seen in Fig. 10 and Tables 4 and 5.

\subsection{Pushover curves for load-based and displacement-based analysis procedures in 3DEC}

Pushover tests can be implemented in 3DEC using either a displacement-based procedure or a load-based procedure. As discussed in 2.3, a displacement-based procedure can be achieved by applying a constant loading velocity and the load-based procedure can be

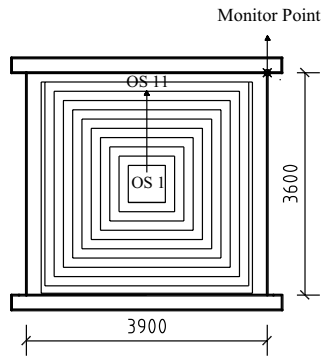

(a) Opening percentages type I

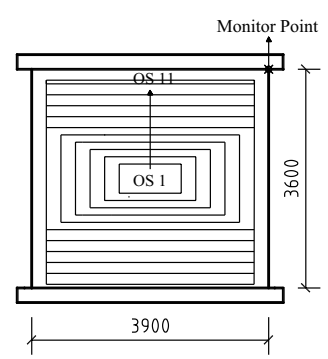

(b) Opening percentage type II

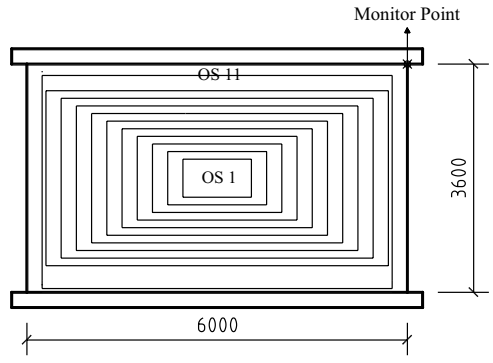

(c) Opening percentage type III

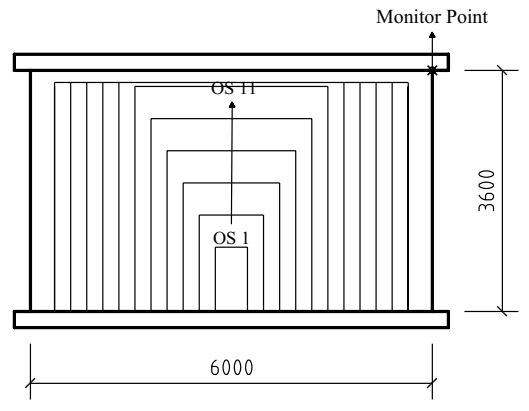

(d) Opening percentage type IV

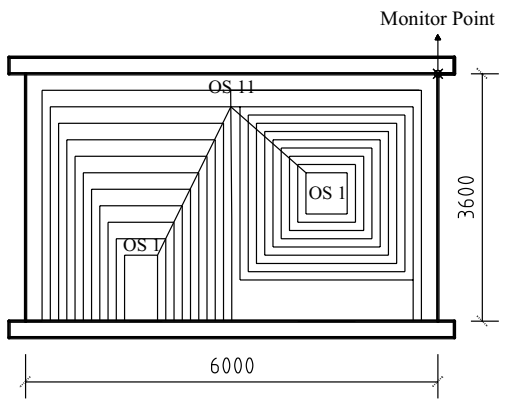

(e) Opening percentage type $\mathrm{V}$

Fig. 10 Opening percentages in the five masonry wall types 


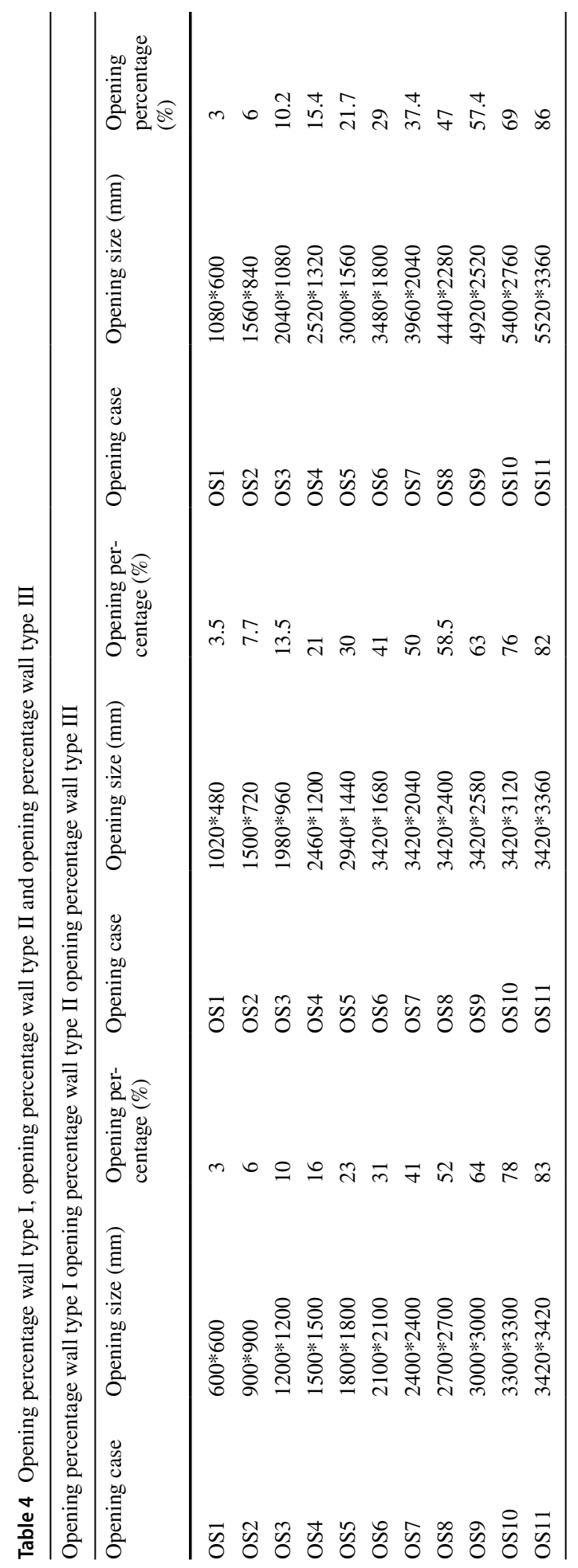


Table 5 Opening percentage wall type IV and opening percentage wall type V

\begin{tabular}{llllll}
\hline Opening percentage wall type IV opening percentage wall type V \\
\hline Opening case & Opening size $(\mathrm{mm})$ & $\begin{array}{l}\text { Opening } \\
\text { percentage } \\
(\%)\end{array}$ & Opening case & Opening size $(\mathrm{mm})$ & $\begin{array}{l}\text { Opening } \\
\text { percentage } \\
(\%)\end{array}$ \\
\hline OS1 & $480 * 960$ & 2 & OS1 & $480 * 960$ and $600 * 600$ & 3.8 \\
OS2 & $960 * 1440$ & 6.4 & OS2 & $720 * 1200$ and $840 * 840$ & 7.3 \\
OS3 & $1440 * 1920$ & 12.8 & OS3 & $960 * 1440$ and $1080 * 1080$ & 11.8 \\
OS4 & $1920 * 2400$ & 21.3 & OS4 & $1200 * 1680$ and & 17.4 \\
OS5 & $2400 * 2880$ & 32 & OS5 & $1440 * 1920$ and & 24 \\
OS6 & $2880 * 3360$ & 44.8 & OS6 & $1680 * 2160$ and & 31.6 \\
OS7 & $3360 * 3420$ & 53.2 & OS7 & $1920 * 2400$ and & 40.6 \\
OS8 & $3840 * 3420$ & 60.8 & OS8 & $2160 * 2640$ and & 50 \\
OS9 & $4320 * 3420$ & 68.4 & OS9 & $2400 * 2880$ and & 61.4 \\
OS10 & $4800 * 3420$ & 76 & OS10 & $2520 * 2520$ & $4800 * 3420$ \\
OS11 & $5280 * 3420$ & 83.6 & OS11 & $5280 * 3420$ & 76 \\
\hline
\end{tabular}

achieved by applying a horizontal acceleration. For the load-based procedure, vertical load was applied first, then a horizontal acceleration was applied in increments until the wall failed. For the displacement-based procedure, again the vertical load was applied first then, using a loading block attached to the concrete beam at the top of the wall, a constant velocity was applied until the wall collapsed. For both loading procedures the displacement of the top block (concrete beam) and the applied load/acceleration was recorded so the pushover curves could be determined, as shown in (Fig. 11).

Because the loading conditions for the two analysis regimes are different, the resulting pushover curves are not expected to be identical, however both methods give useful insights into the wall behaviour. The load-based procedure gives a higher prediction of seismic capacity at collapse and it better reflects the loading that would be

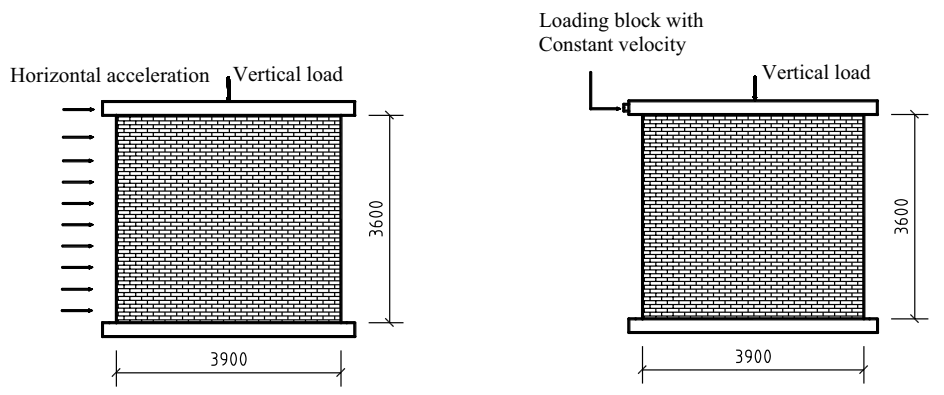

(Left) Load pattern for load-based pushover analysis; (Right) Load pattern for displacement-based pushover analysis;

Fig. 11 Pushover loading patterns for the two procedures and their relationship 
applied during a seismic event. However, the displacement-based approach is useful to investigate post peak response and is more representative of most experimental tests. It is worth noting that there is also a significant difference in the computational cost of the two analysis methods. Using the solid wall as an example, the load-based procedure required $202 \mathrm{k}$ analysis cycles while the displacement-based procedure required $\sim 523 \mathrm{k}$ analysis cycles to complete (just over twice as long). A larger number of cycles was necessary for the displacement-based approach as it was important to apply the loading slowly enough that the analysis replicated a pseudo-static loading condition. However, the analysis duration for the displacement-based approach only averaged $1 \mathrm{~h}$ so both analysis procedures were viable. Therefore, in this paper, both methods were used to determine the in-plane capacity of masonry walls with different opening percentages with the aim of identifying appropriate equations for the capacity reduction as the opening size increases. The pushover curves for masonry wall type I with different opening percentages, analysed using the two procedures, are given in Fig. 12. For both methods the analytical parameters (damping and load/velocity increments) were chosen to optimize the numerical stability of the analyses while limiting analysis time. Generally, the results were insensitive even to significant changes in the analysis parameters suggesting that a significant proportion of the irregularity of the response in Fig. 12 is coming from the development of sudden tensile failures between bricks as the analyses progress.

The pushover curves created using a load-based procedure develop relevant smooth curves up to the point of maximum base shear force, at which point the displacement of the walls increases dramatically as the walls fail. For an opening percentage under $\sim 10 \%$, the base shear force of masonry wall is practically the same as for the solid wall. When the opening percentage is more than $\sim 15 \%$ the wall capacity starts to drop significantly as the opening size increases. When the opening percentage is $\sim 65 \%$ the wall only retains $15 \%$ of its solid capacity. For the displacement-based loading procedure, the pushover curves are quite similar, but the maximum values are lower. For an opening percentage over $\sim 10 \%$ the decreasing wall capacity becomes obvious. When the opening percentage reaches $\sim 40 \%$ the wall in-plane capacity has reduced by $\sim 40 \%$. Once the opening percentage exceeds $\sim 60 \%$, the in-plane capacity has reduced to less $20 \%$ of the solid capacity.

The relationships between the opening size and the peak in-plane capacity for the two loading procedures are shown in Fig. 13 (left). Walls with openings less than $10 \%$ analysed using a load-based procedure have a much higher capacity than those analysed
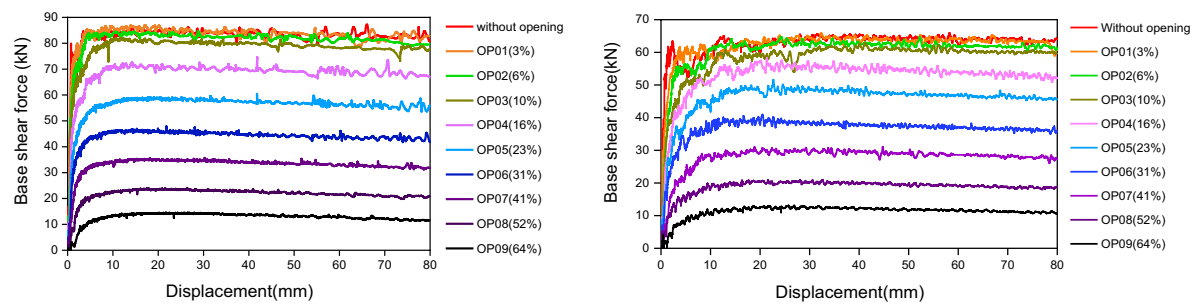

(Left) Pushover curves resulting from load-based analyses; (Right) Pushover curves resulting from displacement-based analyses

Fig. 12 The pushover curves for Case I masonry wall with different opening percentage for the different analysis procedures 

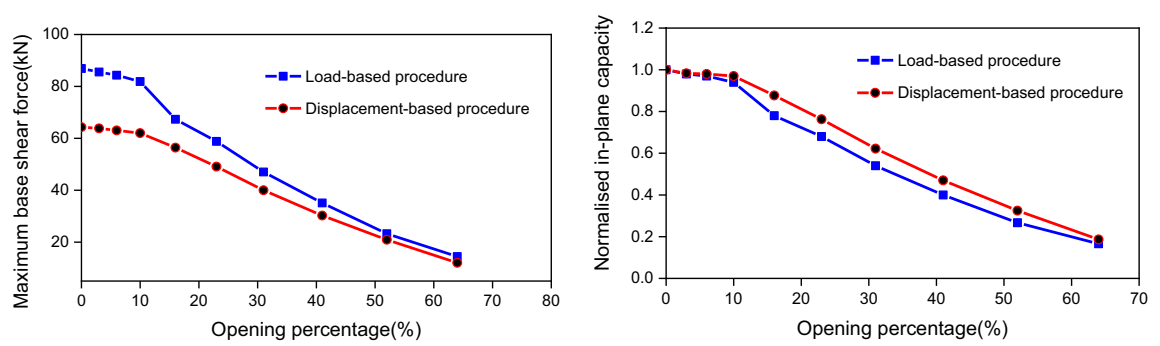

(Left). Impact curves of opening percentage on maximum base shear force for the load and displacement-based procedure; (Right). Impact curves of opening percentage on normalised wall capacity for the load and displacement-based procedure

Fig. 13 Comparison of the impact of opening percentage on wall capacity for the load and displacementbased analysis procedures

using a displacement-based procedure, however as the opening percentage increases, the difference between the two methods reduces. When the opening size is greater than $40 \%$, the capacity of the wall under both analysis methods is similar.

To allow further comparison between the results from the two loading procedures, for each procedure the pushover curves were normalised relative to the peak base shear force of the solid wall Fig. 13 (right). Both analysis methods result in very similar normalised curves for openings sizes up to $10 \%$ but the capacities from load-based procedure do drop below those from the displacement-based procedure once the opening is greater than $10 \%$.

To highlight the differences in the in-plane behaviour for the two analysis procedures, the crack patterns for four different opening percentages are shown in Table 6. The crack patterns for the walls produced by the two analysis procedures both show similar global failure mechanisms for the different opening percentages, however, some local differences can be observed. In particular, the masonry walls analysed using a load-based procedure generally display smaller distributed cracks compared to the walls analysed using a displacement-based procedure. The local differences in the failure patterns are a result of the different ways that the loading is applied to the walls. For the load-based analysis each brick is subjected to a force proportional to its mass, resulting in a very distributed loading applied the whole wall and more distributed cracking. However, for the displacementbased analysis method the loading is applied across the wall as a whole resulting in fewer larger cracks.

\subsection{Comparison between relationships for in-plane capacity and opening percentage for URM walls with previous research}

It is worth noting that in most experimental tests, a displacement-based procedure is used to load masonry walls, as it is much harder to conduct a test using a load-based procedure (such tests requiring the use of a shaking table). Therefore, most experimental data comes from displacement-based pushover tests. In addition, because no previous research has focused on the effects of openings in URM, data from pushover tests of RC infill walls showing the relationship between in-plane capacity and opening percentage, from Asteris (2003), Giannakas et al. (1987), has been used to provide some comparison with the numerical results produced by 3DEC for URM walls. Curves showing the relationship between stiffness reduction and opening percentage are shown in Fig. 14. These curves show that the experimental performance of masonry walls in $\mathrm{RC}$ frames and equivalent 
Table 6 In-plane crack patterns for masonry walls with different opening percentages analysed using loadbased and displacement-based procedures at $4 \%$ drift $(0.15 \mathrm{~m})$

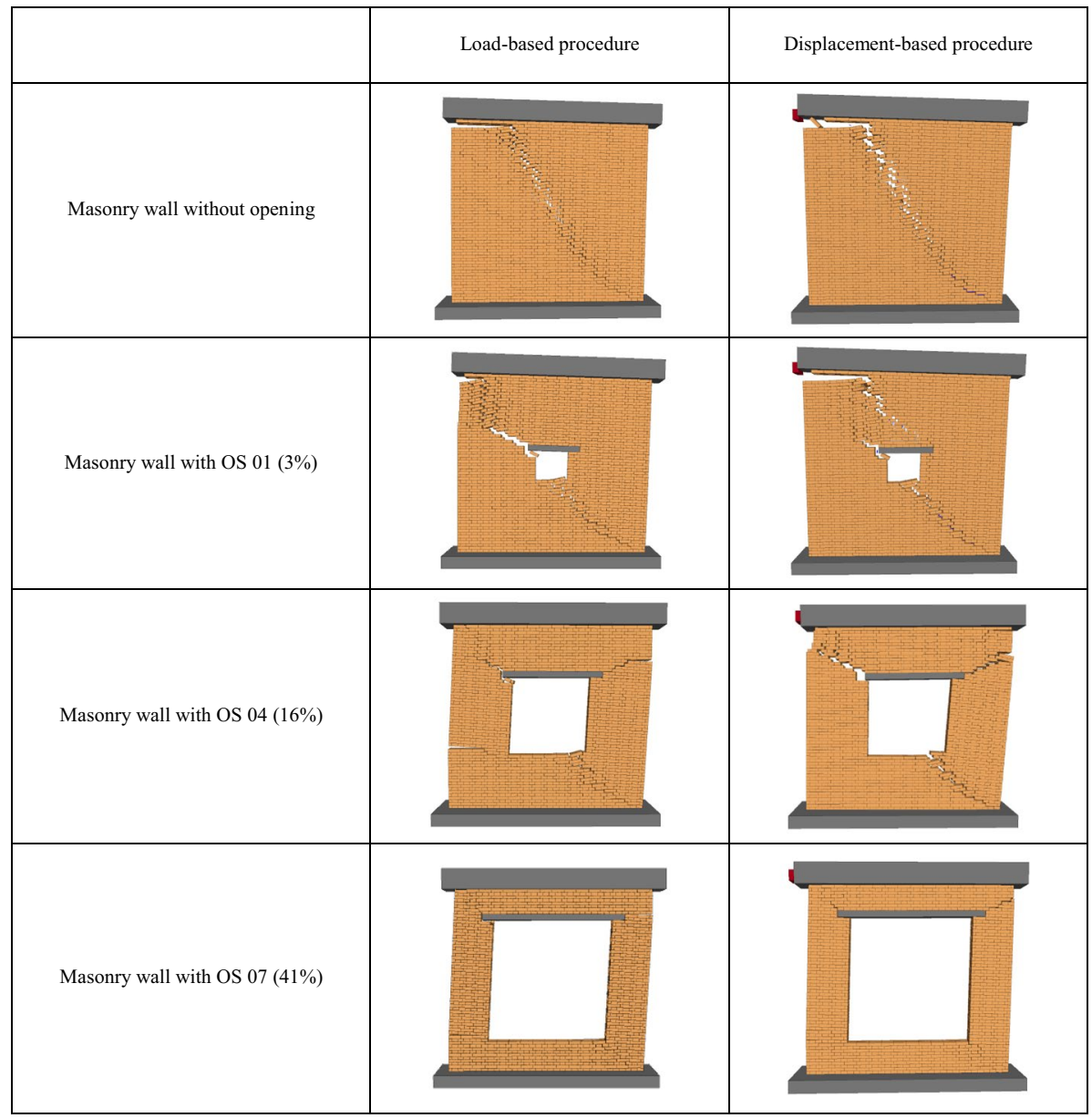

displacement-based analytical solutions in 3DEC for URM walls are very similar, while the load-based analysis procedure in 3DEC predicts a higher in-plane performance for walls with the same opening percentage. For RC frame infill walls, when the percentage opening is greater than $50 \%$ the RC frame starts to carry all the load and there is no further degradation in wall stiffness while for the URM walls the stiffness continues to decrease. This load sharing mechanism between frame and masonry does not exist in URM walls. While the results from the load-based analyses of the URM walls do not match the displacementbased experimental data for RC infill walls, the load-based analysis results should not be dismissed because they reflect a loading pattern that is closer to that which would occur under seismic conditions. Therefore, both pushover procedures should be considered when designing or assessing URM.

Overall, the curves for URM produced by 3DEC show a similar trend to those given in previous papers. However, there are still some limitations in this comparison as the RC frame infilled walls eventually display different failure mechanisms because of load sharing between the RC frame and the masonry wall. 


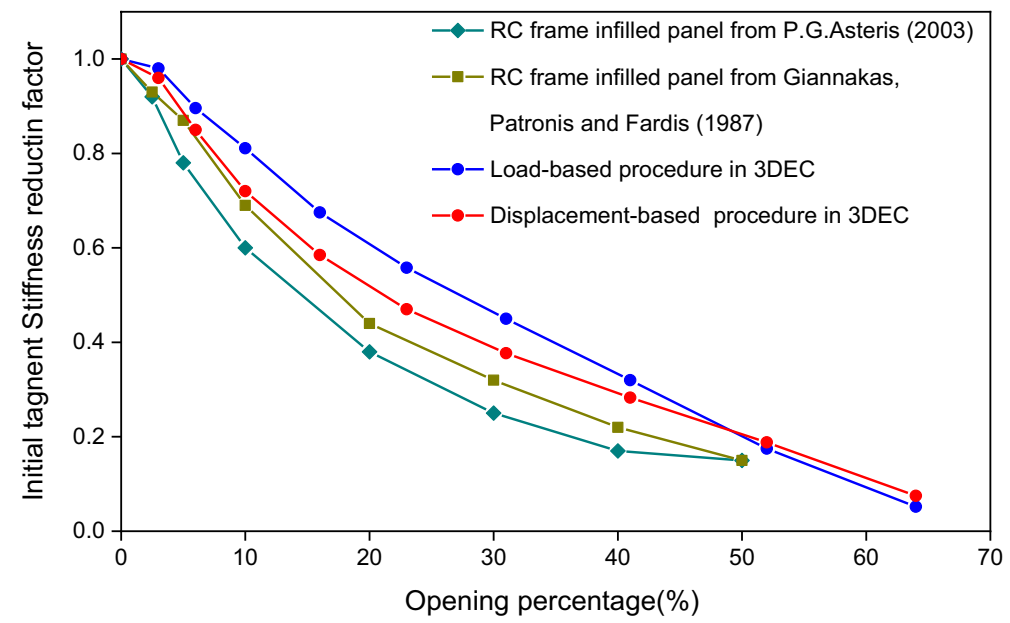

Fig. 14 Comparison of the relationship between initial tangent stiffness and opening percentage based on experimental data and 3DEC analyses

\subsection{Effects of opening percentage for different shaped openings and walls}

As mentioned in 5.1, five types of 3DEC model were built to identify the impact of opening percentage on a variety of URM walls; centralised square and rectangular window openings, single door openings, and combined door and window openings. Because loadbased analysis procedures give a better representation of the inertial loading caused by earthquakes pushover curves were only generated using the load-based analysis procedures and normalised curves showing the relationship between the maximum in-plane capacity and the opening percentage were calculated. In all cases the peak in-plane capacity of the walls reduces as the size of the opening increases, although the rate of drop varies. As shown in Fig. 15a, the capacity of the square and rectangular walls with central openings (cases I, II and III) follow a similar trend, with the in-plane capacity starting to drop significantly when the opening percentage exceeds $\sim 10 \%$ until the opening percentage is $\sim 65 \%$ at which point a residual wall capacity of $\sim 10 \%$ is reached. For Case II (rectangular central opening in a square wall), the in-plane capacity is similar that to Case I (square opening in

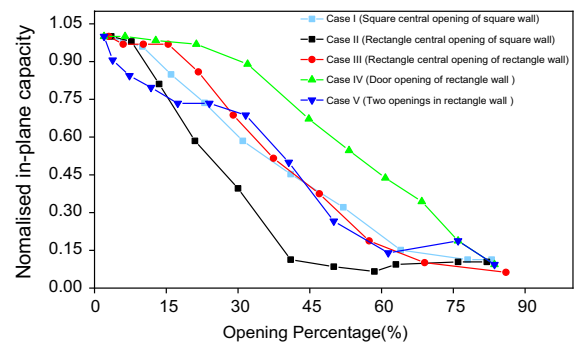

(a)

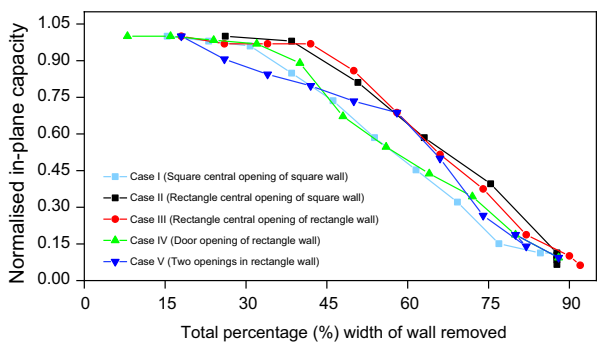

(b)

Fig. 15 The relationships between residual in-plane capacity and $\mathbf{a}$ opening percentage, $\mathbf{b}$ total percentage (\%) width of wall removed for various opening cases 
square wall) when the opening percentage is below $10 \%$, however above that percentage the wall capacity drops quickly until at a $40 \%$ opening percentage only a residual capacity of $\sim 10 \%$ of the solid wall remains. However for Case IV (door opening) the in-plane capacity remains higher than for the other cases for the same opening percentage, and it only drops to a $10 \%$ residual capacity when the opening percentage exceeds $80 \%$. For Case V (door and window openings) the wall capacity reduces dramatically even with a relatively small opening percentage however once then the opening percentage is greater than $20 \%$, the curve follows a similar trend to Case I and III.

The differences in capacities for the cases shown in (Fig. 15a) can be explained by looking at the failure patterns of masonry walls, shown in Table 7. Cases I and III display very similar failure mechanisms, the cracking starting on one diagonal and progressing to both diagonals as the opening percentage increases although the opening percentage at which

Table 7 In-plane crack patterns for URM walls with different opening percentages at $4 \%$ drift $(0.15 \mathrm{~m})$

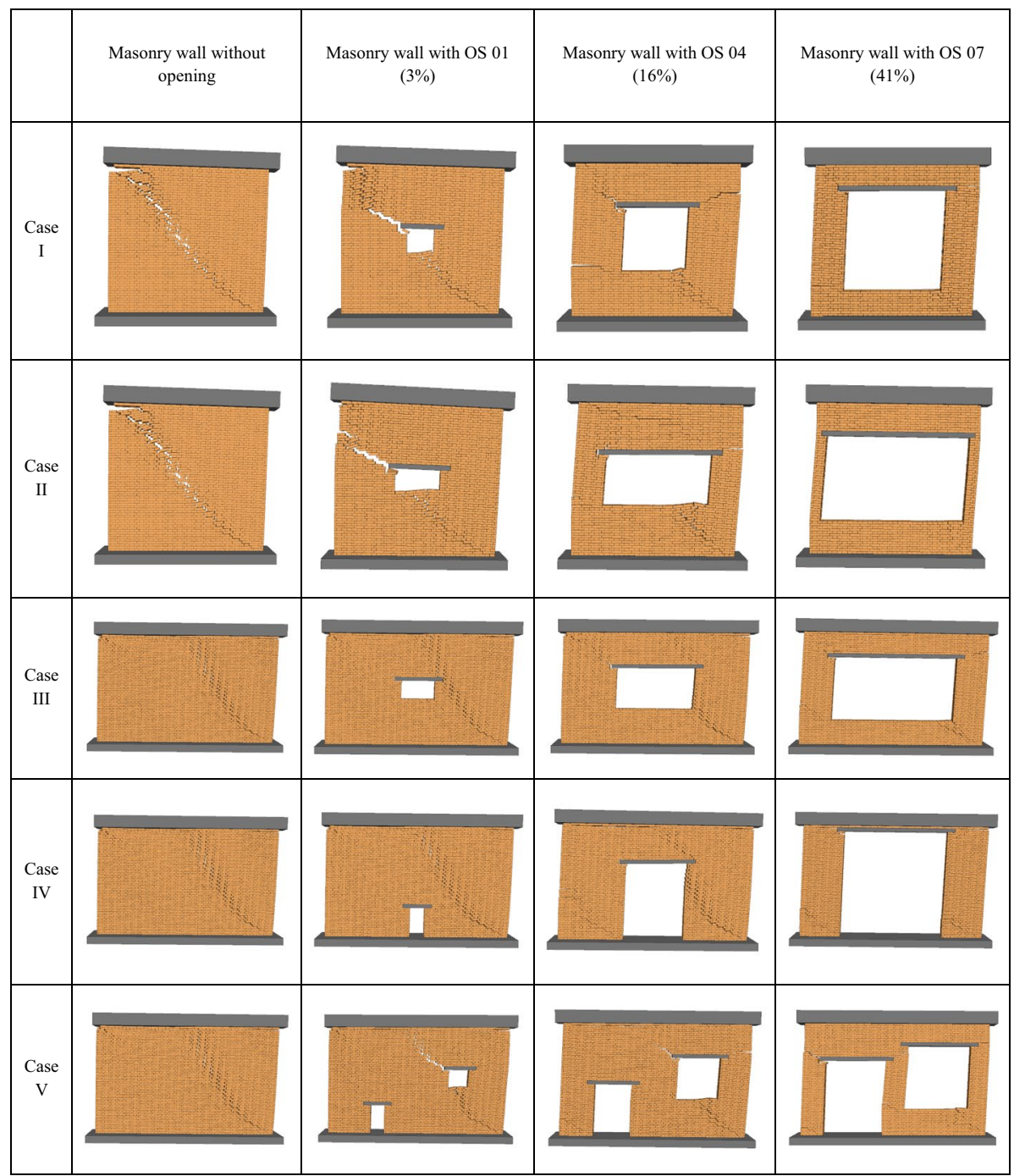


the behaviour changes does vary between the two cases. Case II, displays a different behaviour compared to Cases I and II because the masonry piers on either side of the opening are proportionately thinner for the same opening percentage. This leads to quicker localised failure of the piers and a reduced capacity for any specific opening percentage. For Case IV, the reverse is true as the piers around the door remain relatively wide while the spandrel becomes rapidly thinner as the percentage opening increases. In this case the masonry piers remain strong enough to resist the horizontal force and the wall performance is better than for the other cases. Therefore, as an alternative to considering the effect of the opening percentage on the wall capacity (Fig. 15b) shows the wall capacities compared to the total percentage width of wall removed by all the openings. This criterion reduces the differences in the curves for the more asymmetric opening cases i.e. the rectangular opening in a square wall and the two openings in one wall (Cases II and IV), but increases the variation for the more regular walls (Cases I and III). In Case V, the location of the small window opening coincides with the crack location in the solid case inducing a localised failure at the window corner even though the opening percentage is small. The wall behaviour becomes more similar to Case III as the opening percentage increases. This case shows the importance of the opening position, an aspect which is studied further in Sect. 6.

In summary, as the opening percentage increases the in-plane capacity reduces, often with changes to the failure mechanism. URM walls analysed using a force-based procedure show better capacity compared to walls analysed using a displacement-based procedure for the same opening percentage. For walls with the same opening percentage an adverse shape or location for the opening can result in significantly lower lateral strength and displacement capacity. Notably, the masonry walls with both door and window openings did not perform well even at small opening percentages which is of concern as this arrangement is common in real structures.

\section{In-plane capacity of masonry walls with openings in different positions}

\subsection{Cases considered to determine the effect of opening location on in-plane capacity}

As seen above, variation in the position of an opening in a URM wall can result in a change to the wall failure mechanism, creating more local failures and less wall integrity. To further evaluate the effect of opening position on the in-plane capacity of masonry walls, one model (Case I) was built in 3DEC and many different opening positions were considered, see Fig. 16. For this wall, nine opening positions (A1 to C3) were considered and analysed using both load-based and displacement-based pushover procedures with loading being applied left to right as shown in (Fig. 11).

\subsection{The in-plane capacity of masonry walls with openings in different positions}

To visualise the change in wall capacity for different opening positions using a load-based analysis procedure, contour plots of the wall strength capacity are potted based on the centre point of the opening, see (Fig. 17). Similar plots using a displacement-based analysis procedure are shown in (Fig. 18). 
Fig. 16 Geometry for 3DEC models showing opening positions considered for Case I wall

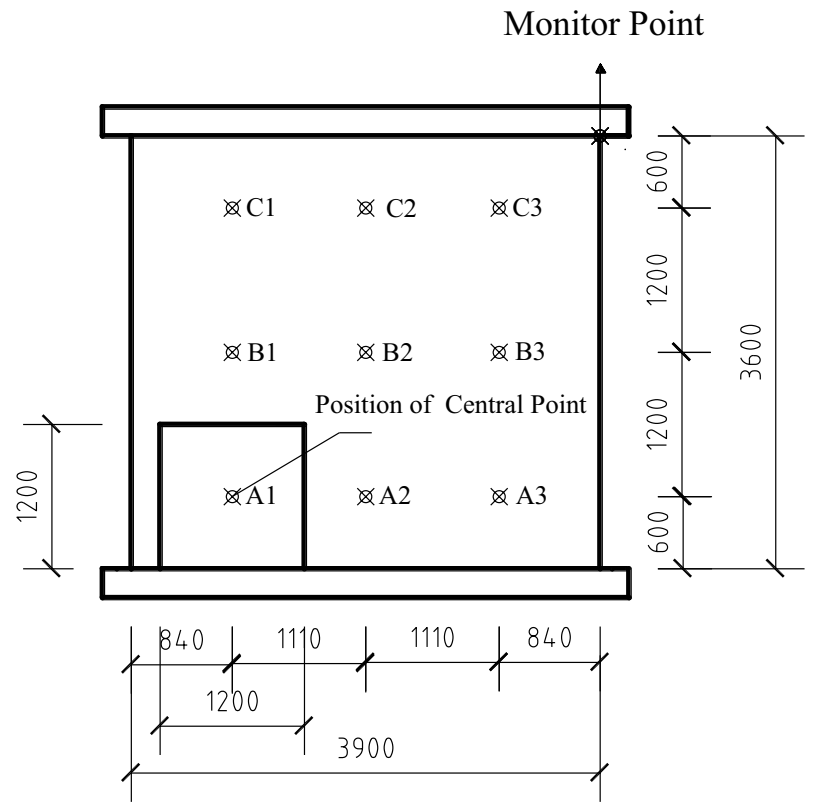

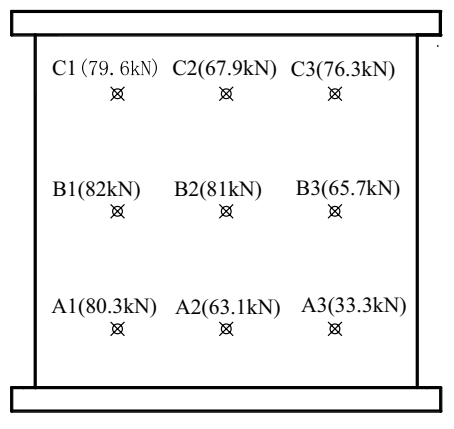

(a)

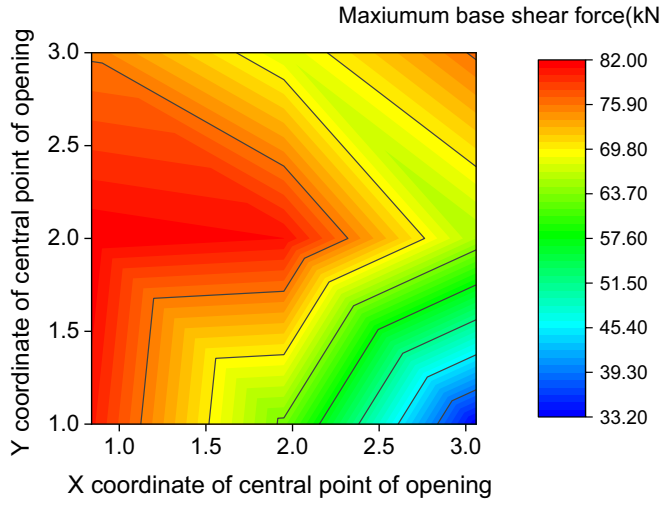

(b)

Fig. 17 a Maximum base shear forces for the Case I wall for the 9 different opening positions. b Contour plot of maximum in-plane strength capacity of the wall for different opening positions; analysed using a load-based analysis procedure

Figure 17 shows that, for a load-based analysis, the in-plane capacity of the wall with an opening in the left or middle is higher than when the opening is in the right-hand side of the wall. The maximum capacity of the wall is lowest when the opening is located at the bottom right end of the compression diagonal pattern. Figure 18 shows that the displacement-based analysis procedure results in similar distributions of in-plane capacity for the various opening positions although the wall capacities are lower for this analysis procedure. 


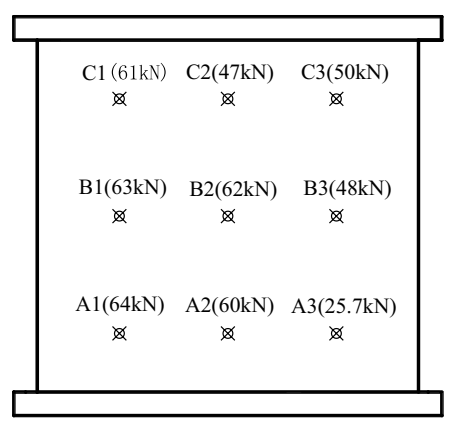

(a)

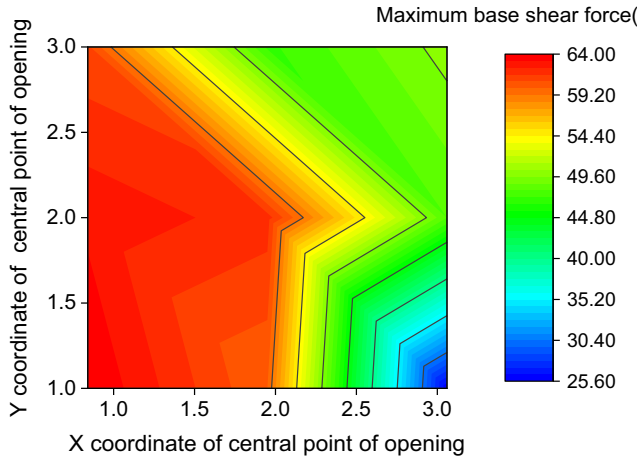

(b)

Fig. 18 a Maximum base shear forces for the Case I wall for the 9 different opening positions. b Contour plot of maximum in-plane strength capacity of the wall for different opening positions; analysed using a displacement-based analysis procedure

In order to compare the differences of in-plane strength capacity for the two analysis approaches more easily, the ratios of the normalised in-plane capacity calculated using the load and the displacement-based methods are shown in Fig. 19. This figure shows that the different analysis approaches generally produce similar distributions in both walls. The range of ratios varies from 1.1 to 1.5 but for most opening positions the difference in capacity from the two analysis methods is close 1.3. The only real differences are that for a displacement-based analysis an opening in the top right has a much worse impact on the wall capacity compared to a load-based analysis and while the reverse is true for an opening in the bottom middle of the wall. Overall, a central opening has the least impact in the wall performance, openings on the right side of the wall reduce the wall capacity, with openings in the bottom of the compression diagonal having a significant impact on the wall capacity.

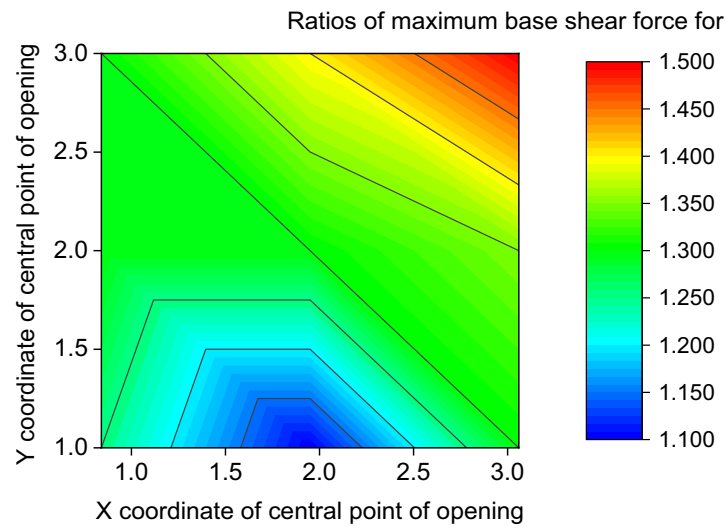

Fig. 19 Ratio of the maximum in-plane capacity calculated using load and displacement-based methods for the Case I wall 


\subsection{Failure crack patterns in masonry walls with openings in different positions}

In order to explore the reasons for the difference in results from the two analysis procedures the crack patterns that have developed the Case I wall, once the wall drift reaches $4 \%$ drift $(0.15 \mathrm{~m})$, are shown in Table 8 .

The variations in crack patterns shown in Table 8 help to explain the differences in the in-plane capacity calculated by the two methods and also show why locating the opening in the top left or bottom right of the wall has such a large effect on the wall capacity.

For opening position $\mathrm{C} 3$ [where the difference in-plane capacity calculated by the two analysis methods is largest (see Fig. 19)], the crack patterns in the masonry wall are different. Using displacement-based analysis results in localised cracking below the opening whereas for the load-based analysis the crack runs as one diagonal through the wall. For opening position A3, again there is an obvious difference in the behaviour of the walls, the masonry wall analysed using a load-based procedure displaying more distributed cracking than the wall analysed using a displacement-based procedure. These results again highlight the importance of accounting for the way the loading is applied to the walls. For the loadbased analysis where each brick is subjected to a force proportional to its mass, the distributed loading applied the whole wall results in more distributed cracking. However, for the displacement-based analysis method where the loading is applied across the wall as a whole this results in fewer larger localised cracks. These differences are emphasised when the opening is moved closer to the edges of the wall as any change to a local failure pattern leads to a significant change in wall capacity.

In summary, the in-plane capacity of masonry walls is sensitive to both location and size of the opening. Both displacement-based and load-based analysis methods can be used to analyse the performance of masonry walls. The masonry walls analysed using a displacement-based procedure (standard push-over method) were sensitive to local failures and generally showed a lower in-plane capacity compared to identical walls analysed using a load-based procedure. The pushover tests analysed using a load-based procedure are a better representation of seismic loading, but this analysis method does not allow tracking of the response of the wall past its peak capacity. Therefore, a combination of both analysis methods is useful for identifying the capacity of URM walls with openings.

\section{Conclusions}

This paper presents the impact of opening size and position on the in-plane capacity of URM walls. A DEM micro modelling approach was used to parametrically analyse several URM walls containing openings. The wall capacities have been calculated using pushover analyses following both load-based and displacement-based procedures. The key conclusions from this research are:

- DEM (using 3DEC) can successfully simulate the quasi-static response of URM walls. This modelling approach allows observation of the progression of the failure patterns up to, and beyond, the collapse of the walls.

- The relationship between opening size and the capacity of a URM wall has been evaluated. The in-plane capacity of masonry walls decreases as the opening size increases, but the specific relationship between the lateral capacity of the walls and opening per- 
Table 8 In-plane crack patterns for Case I wall with different opening locations when wall drift reaches 4\% $(0.15 \mathrm{~m})$

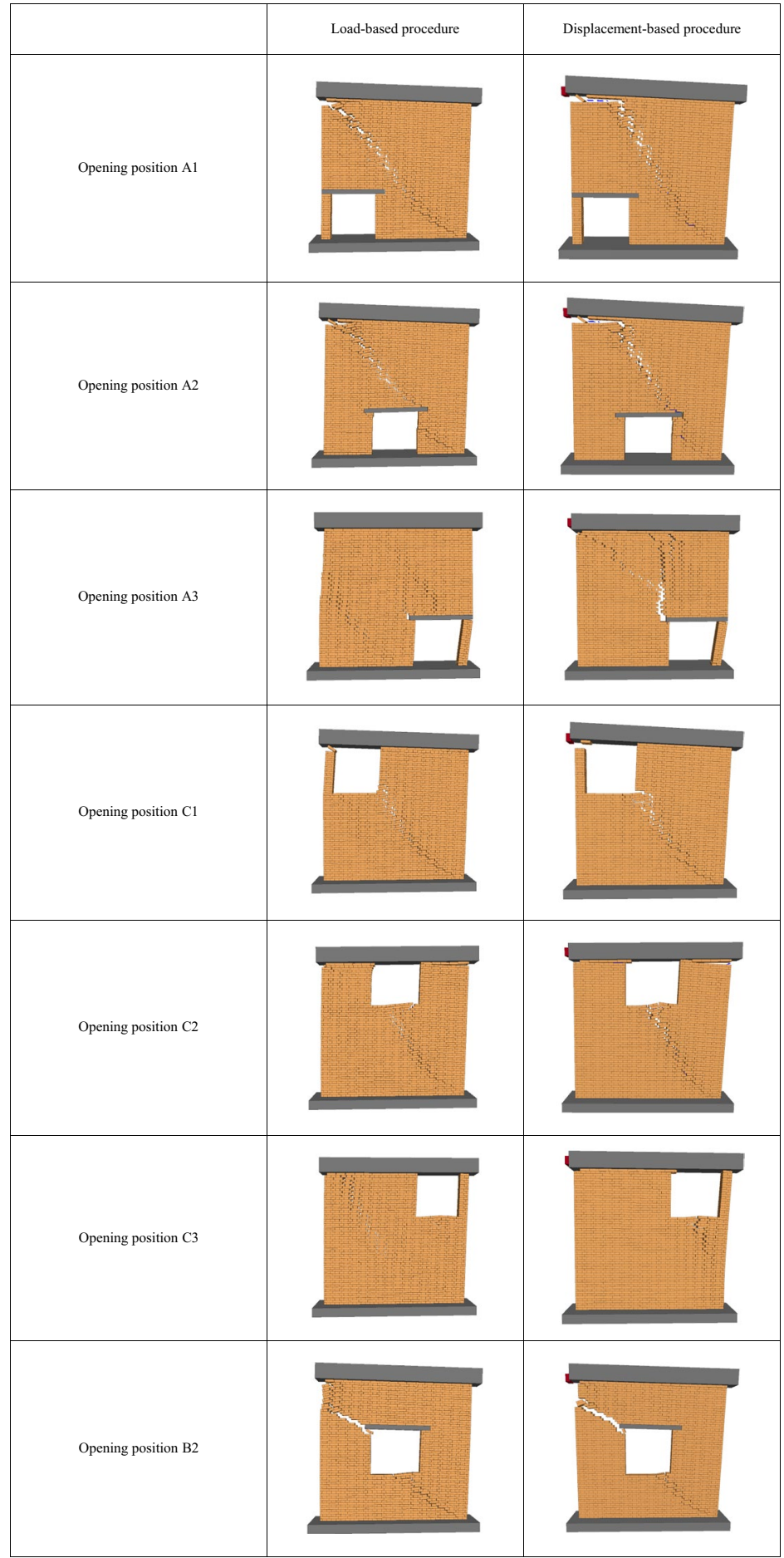


centage depends on the analysis method used and the location of the opening. However, URM walls analysed using a load-based procedure consistently have a high capacity than walls analysed using a displacement-based procedure for an opening percentage less than $40 \%$. When the opening size is greater than $40 \%$, the capacities calculated from the two methods are similar.

- A variation in the number and shape of the opening(s) often changes the failure mechanism in URM (even when the percentage area of the opening remains constant) and may lead to soft storey type failures, significantly reducing the wall strength.

- For walls with a central opening, when the opening percentage is less than $\sim 10 \%$ the wall retains $>80 \%$ of the solid wall capacity. Once the opening exceeds $\sim 50 \%$, only about $10 \%$ residual wall capacity remains.

- DE modelling allows the crack patterns in masonry walls to be observed clearly and there is a clear link between the failure mechanisms and the in-plane capacity of the masonry walls. The differences in the pushover curves developed for different opening percentages directly reflect differences in the crack propagation within the walls. Diagonal cracking and rocking are the major failure mechanisms for URM walls under in-plane loading. In general, the masonry walls analysed using a load-based procedure show more distributed cracking than those analysed using a displacement-based procedure.

- For simple pushover analyses the direction of applied loading needs to be considered when evaluating failure patterns for in-plane loading. The in-plane wall capacity is reduced when the openings are located along in the line of the compression diagonal strut compared to when the opening is the location along the other diagonal.

- The difference in the performance of URM walls (with opening in different positions) calculated using load and displacement-based procedures comes from the fact that under the displacement-based procedure a uniform force is applied across the whole wall, whereas for a load-based analysis, the load is applied at every single block, which tends to lead to more distributed failures.

- For this work the masonry bricks were modelled as rigid blocks and the possibility of any crushing of the bricks was ignored because for most URM walls the behaviour is controlled by the properties of joints. However, the behaviour of masonry walls is sensitive to joint properties and vertical preload so further sensitivity studies may be needed.

This research shows that the size and location of openings in URM walls can have a significant effect on the in-plane capacity of the wall. Pushover analyses are useful tools for the assessment of URM wall capacities, but it is worth noting that load-based procedures and displacement-based procedures produce different results and that a combination of both types of analysis is useful to determine both the failure mechanisms and the capacities of URM walls.

Open Access This article is licensed under a Creative Commons Attribution 4.0 International License, which permits use, sharing, adaptation, distribution and reproduction in any medium or format, as long as you give appropriate credit to the original author(s) and the source, provide a link to the Creative Commons licence, and indicate if changes were made. The images or other third party material in this article are included in the article's Creative Commons licence, unless indicated otherwise in a credit line to the material. If material is not included in the article's Creative Commons licence and your intended use is not permitted by statutory regulation or exceeds the permitted use, you will need to obtain permission directly from the copyright holder. To view a copy of this licence, visit http://creativecommons.org/licenses/by/4.0/. 


\section{References}

Abrams DP, Shah N (1992) Cyclic load testing of unreinforced masonry walls. Illinois University at Urbana Advanced Construction Technology Center

Al-Chaar G, Lamb GE, Issa M (2003) Effect of openings on structural performance of unreinforced masonry infilled frames. ACI Spec Publ 211:247-262

Alexandris A, Protopapa E, Psycharis I (2004) Collapse mechanisms of masonry buildings derived by the distinct element method. In: Proceedings of the 13th world conference on earthquake engineering. Citeseer, pp 1-6

Asteris P (2003) Lateral stiffness of brick masonry infilled plane frames. J Struct Eng 129:1071-1079

Asteris PG, Cavaleri L, Di Trapani F, Sarhosis V (2016) A macro-modelling approach for the analysis of infilled frame structures considering the effects of openings and vertical loads. Struct Infrastruct Eng 12:551-566

Augenti N, Parisi F, Prota A, Manfredi G (2010) In-plane lateral response of a full-scale masonry subassemblage with and without an inorganic matrix-grid strengthening system. J Compos Constr 15:578-590

Basset-Salom L, Guardiola-Víllora A (2014) Seismic performance of masonry residential buildings in Lorca's city centre, after the 11th May 2011 earthquake. Bull Earthq Eng 12:2027-2048

Bruneau M (1994) Seismic evaluation of unreinforced masonry buildings-a state-of-the-art report. Can J Civ Eng 21:512-539

BS EN1998-1 (2004) Eurocode 8 part 1: design of structures for earthquake resistance. General rules, seismic actions and rules for buildings. ISBN 9780580774997. https://www.standardsuk.com/produ cts/BS-EN-1998-1-2004-A1-2013

Bui T, Limam A, Sarhosis V, Hjiaj M (2017) Discrete element modelling of the in-plane and out-ofplane behaviour of dry-joint masonry wall constructions. Eng Struct 136:277-294

Çaktı E, Saygılı Ö, Lemos JV, Oliveira CS (2016) Discrete element modeling of a scaled masonry structure and its validation. Eng Struct 126:224-236

Chaimoon K, Attard MM (2007) Modeling of unreinforced masonry walls under shear and compression. Eng Struct 29:2056-2068

Cundall PA (1971) A computer model for simulating progressive, large scale movement in blocky rock systems. In: Symposium on ISRM, Nancy, France, Proceedings, pp 129-136

de Felice G (2011) Out-of-plane seismic capacity of masonry depending on wall section morphology. Int J Archit Herit 5:466-482

Dihrou L, Crewe AJ, Liu Z, Taylor CA (2018) Shaking table studies of FRP-reinforced masonry: experimental and numerical results. In: Paper presented at the proceedings of the 16th European conference on earthquake engineering, Thessaloniki, Greece, 18-21 June 2018

Dimitri R, De Lorenzis L, Zavarise G (2011) Numerical study on the dynamic behavior of masonry columns and arches on buttresses with the discrete element method. Eng Struct 33:3172-3188

GB50003-2011 (2012) The national standard of the People's Republic of China; Code for design of masonry structures. Chinese Building and Industry Press, Beijing (in Chinese)

Ghiassi B, Soltani M, Tasnimi AA (2012) A simplified model for analysis of unreinforced masonry shear walls under combined axial, shear and flexural loading. Eng Struct 42:396-409. https://doi. org/10.1016/j.engstruct.2012.05.002

Giamundo V, Sarhosis V, Lignola G, Sheng Y, Manfredi G (2014) Evaluation of different computational modelling strategies for the analysis of low strength masonry structures. Eng Struct 73:160-169

Giannakas A, Patronis D, Fardis M (1987) The influence of the position and the size of openings to the elastic rigidity of infill walls. In: Proceedings of 8th hellenic concrete conference, pp 49-56

Ingham J, Griffith M (2010) Performance of unreinforced masonry buildings during the 2010 Darfield (Christchurch, NZ) earthquake. Aust J Struct Eng 11:207-224

Itasca (2012) 3DEC - three-dimensional distinct element code. Version 5. Itasca Consulting Group, Minneapolis

Kakaletsis D, Karayannis C (2007) Experimental investigation of infilled R/C frames with eccentric openings. Struct Eng Mech 26:231-250

Kakaletsis D, Karayannis C (2008) Influence of masonry strength and openings on infilled R/C frames under cycling loading. J Earthq Eng 12:197-221

Korswagen PA, Longo M, Meulman E, Rots JG (2019) Crack initiation and propagation in unreinforced masonry specimens subjected to repeated in-plane loading during light damage. Bull Earthq Eng 17:4651-4687

Lemos J (1998) Discrete element modelling of the seismic behaviour of stone masonry arches. Comput Methods Struct Mason 4:220-227 
Lemos J (2004) Modelling stone masonry dynamics with 3DEC. In: Konietzky (eds) 1st International UDEC/3DEC symposium: numerical modelling of discrete materials in geotechnical engineering, civil engineering and earth sciences, pp 7-13

Lemos JV (2007) Discrete element modeling of masonry structures. Int J Archit Herit 1:190-213

Lemos J, Campos Costa A (2017) Simulation of shake table tests on out-of-plane masonry buildings. Part (V): discrete element approach. Int J Archit Herit 11:117-124

Liu Z, Crewe AJ (2018) Effect of position and size of openings on the seismic performance of masonry structures. In: Paper presented at the proceedings of the 16th European conference on earthquake engineering, Thessaloniki, Greece, 18-21 June 2018

Lourenco PB (1996) Computational strategies for masonry structures. Delft University of Technology, Delft

Lourenco P, Rots J (1994) Analysis of masonry structures with interface elements. Rep No 03-21-22-0 1

Lourenço PB, Oliveira DV, Roca P, Orduña A (2005) Dry joint stone masonry walls subjected to in-plane combined loading. J Struct Eng 131:1665-1673

Lourenço PB, Avila L, Vasconcelos G, Alves JPP, Mendes N, Costa AC (2013) Experimental investigation on the seismic performance of masonry buildings using shaking table testing. Bull Earthq Eng 11:1157-1190

Magenes G, Calvi GM (1997) In-plane seismic response of brick masonry walls. Earthq Eng Struct Dyn 26:1091-1112

Mohammadi M, Nikfar F (2012) Strength and stiffness of masonry-infilled frames with central openings based on experimental results. J Struct Eng 139:974-984

Parisi F (2010) Non-linear seismic analysis of masonry buildings. Università degli Studi di Napoli Federico II

Parisi F, Augenti N (2013) Seismic capacity of irregular unreinforced masonry walls with openings. Earthq Eng Struct Dyn 42:101-121

Petry S, Beyer K (2015) Limit states of modern unreinforced clay brick masonry walls subjected to in-plane loading. Bull Earthq Eng 13:1073-1095

Sarhosis V, Sheng Y (2014) Identification of material parameters for low bond strength masonry. Eng Struct 60:100-110

Sarhosis V, Oliveira DV, Lemos JV, Lourenço PB (2014) The effect of skew angle on the mechanical behaviour of masonry arches. Mech Res Commun 61:53-59

Sarhosis V, Garrity S, Sheng Y (2015) Influence of brick-mortar interface on the mechanical behaviour of low bond strength masonry brickwork lintels. Eng Struct 88:1-11

Sarhosis V, Bagi K, Lemos JV, Milani G (2016) Computational modeling of masonry structures using the discrete element method. Engineering Science Reference, New York. https://doi. org/10.4018/978-1-5225-0231-9

Voon K, Ingham JM (2008) Experimental in-plane strength investigation of reinforced concrete masonry walls with openings. J Struct Eng 134:758-768

Wilding BV, Beyer K (2017) Force-displacement response of in-plane loaded unreinforced brick masonry walls: the critical diagonal crack model. Bull Earthq Eng 15:2201-2244

Zhang M, Jin Y (2008) Building damage in Dujiangyan during Wenchuan earthquake. Earthq Eng Eng Vib 7:263-269

Publisher's Note Springer Nature remains neutral with regard to jurisdictional claims in published maps and institutional affiliations. 